$15^{\text {th }}$ International Conference on

AEROSPACE SCIENCES \& AVIATION TECHNOLOGY,

$\boldsymbol{A S A T}$ - 15 - May 28 - 30, 2013, Email: asat@mtc.edu.eg, Military Technical College, Kobry Elkobbah, Cairo, Egypt, Tel: +(202) 24025292 -24036138, Fax: +(202) 22621908

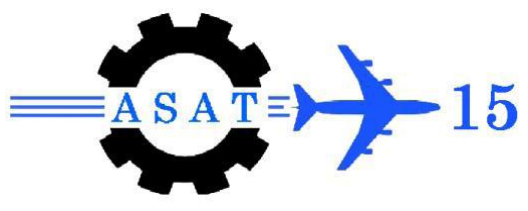

\title{
CLOS Flight Path Design and Analysis
}

\author{
G.A. El-Sheikh ${ }^{*}$, A. N. Oda ${ }^{\dagger}$, A. Al-Gelany ${ }^{\dagger}$, R. Al-Bardeny ${ }^{\dagger}$
}

\begin{abstract}
Antitank guided missiles are commanded to the line of sight (CLOS) against ground and short range armored targets. Among the CLOS guided missile systems is the tubelaunched optically-tracked guided-weapon (TOW) and it belongs to the second generation. This antitank guided missile is considered for the present work to improve its performance via classical and robust synthesis of autopilot. The design and analysis necessitates somehow accurate modeling, linearized models, and autopilot design techniques with different uncertainties. This paper is devoted to the derivation of the system equations of motion clarifying different sources of uncertainty, where the solution of these equations is described in the form of modules programmed within the MATLAB environments. The simulation is conducted with different engagement-range scenarios and validated against some reference data and verified for performance requirements including the time of flight, miss distance, and fin deflections.
\end{abstract}

The missile-control system transfer functions representing the system dynamics in pitch and yaw planes are derived based on the designed 6DOF simulation model. These transfer functions are utilized for classical and robust autopilot design and analysis to clarify its capability to stabilize the system in presence of un-modeled dynamics and satisfy the performance requirements with disturbance rejection and measurement noise attenuation. The final autopilot is then utilized within the 6DOF simulation for evaluation against flight path parameters with previous work and reference flight data. The designed autopilot achieved flight path engagements with higher level of noise than previous works and less miss distance. The future work is concerned with the inclusion of roll channel autopilot in addition to the guidance unit and evaluating the system performance.

Keywords: command guidance systems, CLOS, classical and robust control, uncertainties

\section{Anti-Tank Guided Missile Systems}

Antitank guided missiles (ATGM) are command guidance systems [1] launched against tanks and armored vehicles and they are classified into three generations. The first generation manually tracks both the target and missile using optical telescopes. The second generation manually tracks the target using optical telescopes while the missile is automatically IR tracked via IR sensor in the launcher and IR source strapped on the missile rear.

Consequently, the motion parameters for both the target and missile are transferred automatically into signals applied to the guidance unit. The third generation is characterized by manual or automatic target tracking through optical telescopes, TV, laser or radio devices and the missile is automatically tracked as in the second generation. However, the guidance

\footnotetext{
Head of the Electronics and Communications Department, Pyramids High Institute for Engineering and Technology, 6-October, Cairo, Egypt.

$\dagger \quad$ Egyptian Armed Forces, Egypt.
} 
commands in this generation are transmitted to the missile through a remote link instead of wires. This generation could be of the semi-active homing guidance in which guidance commands are generated onboard.

Within CLOS guidance system an operator or a computer at the control point solves the mission of interception on the basis of obtained coordinates for both target and missile and forms the command, according to the utilized guidance method, for the control system which changes the missile spatial position. A telescope or TV camera based on the parent platform tracks the target and the missile to yield tracking data to be sent to the system guidance computer. The guidance computer compares the tracking data for target and missile and extracts the appropriate guidance commands according to the employed guidance method. These commands are applied to the missile through a wire link during its flight. That is, the guidance of a missile is carried out either totally by the operator or partially by the interaction between human and electronic circuits constituting the guidance unit. According to these features, the antitank command guidance systems are divided into three main subgroups: manual command to line of sight (MCLOS), semi-automatic CLOS (SACLOS) and automatic CLOS (ACLOS) $[1,2,7,8,15]$.

The human operator tracks the target only in the semi-automatic guidance system where the information about the missile is picked from it. The miss-angle between optical sight lines (the first line between tracker and target and the second line between tracker and missile) is automatically determined and the guidance commands are generated and transmitted to the missile for correcting its position in the space until hitting the target. The system under consideration belongs to the second generation, where the gunner acquires the target visually through the optical system of the tracking device, and tracks the target rather by optical or electro-optical means, depending on the conditions of visibility in the operating environment. Deviations of the missile from the intended line-of-sight trajectory are sensed by infrared detectors in the launcher. These detectors receive encoded information from a source in the missile aft-part which is processed in the launcher to provide azimuth and elevation correction commands. These commands are then sent to the missile over the wire link to bring the missile back on course. The missile performs corrective maneuvers by means of aerodynamic control surfaces which deflect in response to these guidance commands. The actuators respond to control signals from the missile electronics which process the pitch and yaw signals from the wire link as well as the roll and yaw signals from an inboard gyro. The propulsion system for the missile employs two separate rocket motors to keep the exhaust gases a safe distance from the gunner. The missile then coasts to the target as shown in Fig. $1[11]$.

The wire command link is a two-wire system wherein single strand, high strength, insulated wire is dispensed from two small diameter bobbins mounted at the aft end of the missile. The wires are wound on the bobbins under tension so that they can be dispensed in a controlled manner which prevents them from becoming tangled or twisted. The circuit to the launcher is completed through the missile case where the link wires are attached to terminals fitted inside it. The missile case contains additional wiring that connects the missile to the launcher through an umbilical connector assembled into the top of the case. This connector is mated when the missile is loaded into the launcher and the retaining clamp is closed, completing the circuits between the missile and launcher. The wire command link provides a passive link for the transmission of steering commands from the launcher to the missile with the additional advantages of low cost and low electrical power requirement. 


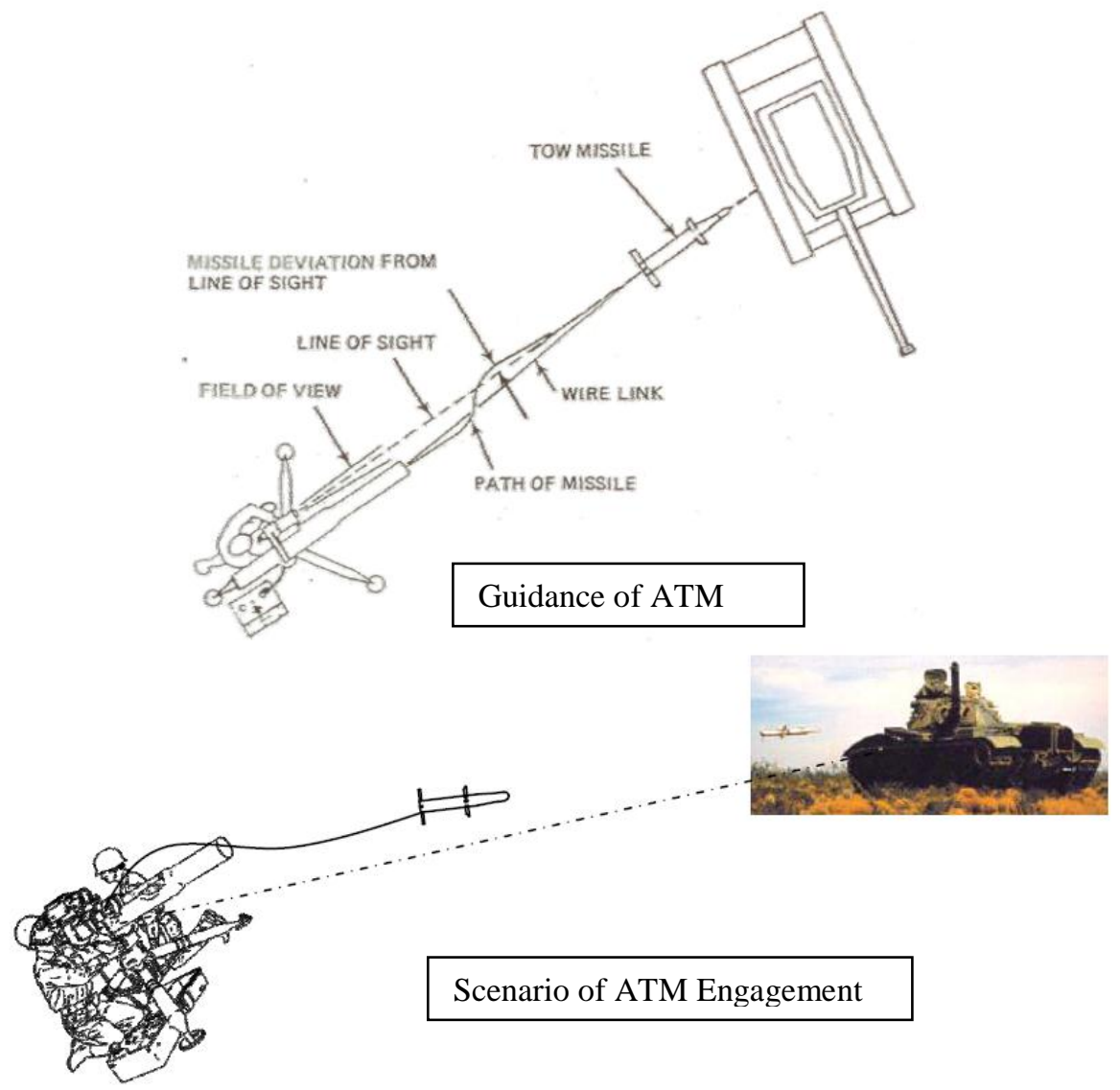

Fig. 1 Guidance and scenario of ATM engagement

The electronics unit receives missile steering signals from the wire command link and missile attitude signals from the gyro, and applies driving voltages to the four control surface actuators. The signals from the single two-axis displacement gyro are shaped and superimposed on the steering signals to achieve missile roll stabilization and reduce the effect of cross winds on missile accuracy at short range. The gyro is activated by cold compressed gas which is stored in a small tank attached to the gyro case. Electrical power for the electronics, infrared sources, and actuator solenoids is provided by thermal batteries as shown in Fig. 2.

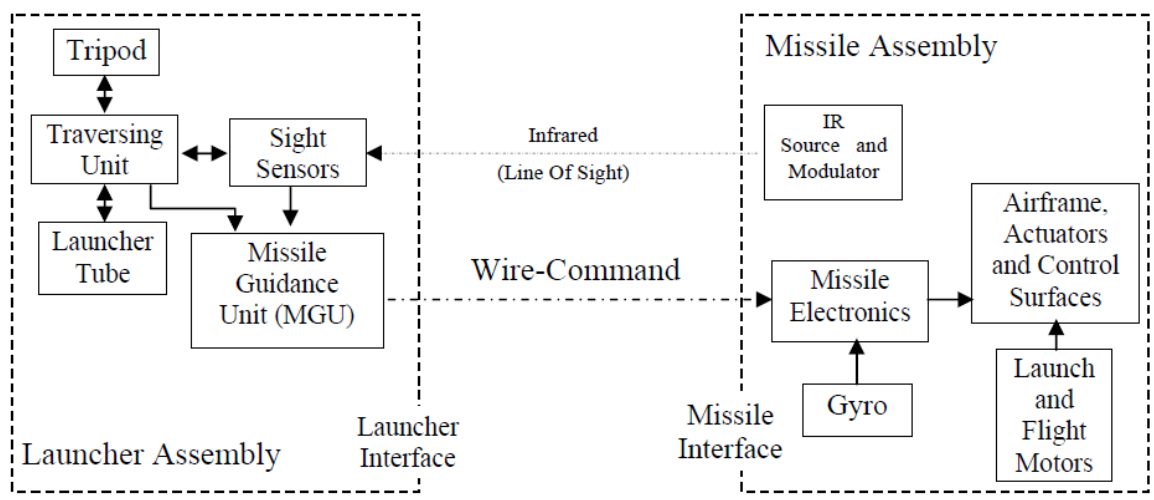

Fig. 2 System control signal flow for antitank guided missile 


\section{Missile Flight Modeling}

\subsection{Reference Frames and Transformation}

When formulating and solving problems of flying vehicles, coordinate systems and reference frames have to be considered for the description of the various dynamical parameters including position, velocity, acceleration, forces, and moments, Figs. 3, 4. The forces acting on the missile (flying vehicle) are weight, thrust, and aerodynamic forces. These forces have different mother frames of reference and consequently coordinates transformation from a frame to another is indispensable. This transformation is carried out using Euler's angles transformation method. The coordinates' transformation from body into the ground coordinate system using Euler's angles can be carried out using the following transformation matrix:

$$
\begin{aligned}
& {\left[\begin{array}{l}
\mathrm{x}_{\mathrm{g}} \\
\mathrm{y}_{\mathrm{g}} \\
\mathrm{z}_{\mathrm{g}}
\end{array}\right]=\mathrm{T}_{\mathrm{bg}}\left[\begin{array}{l}
\mathrm{x}_{1} \\
\mathrm{y}_{1} \\
\mathrm{z}_{1}
\end{array}\right]=\left[\begin{array}{ccc}
\mathrm{c} \psi \mathrm{c} \theta & -\mathrm{s} \psi \mathrm{c} \phi+\mathrm{c} \psi \mathrm{s} \theta \mathrm{s} \phi & \mathrm{s} \psi \mathrm{s} \phi+\mathrm{c} \psi \mathrm{s} \theta \mathrm{c} \phi \\
\mathrm{s} \psi \mathrm{c} \theta & \mathrm{c} \psi \mathrm{c} \phi+\mathrm{s} \psi \mathrm{s} \theta \mathrm{s} \phi & -\mathrm{s} \phi \mathrm{c} \psi+\mathrm{s} \psi \mathrm{s} \theta \mathrm{c} \phi \\
-\mathrm{s} \theta & \mathrm{s} \phi \mathrm{c} \theta & \mathrm{c} \theta \mathrm{c} \phi
\end{array}\right]\left[\begin{array}{l}
\mathrm{x}_{1} \\
\mathrm{y}_{1} \\
\mathrm{z}_{1}
\end{array}\right]} \\
& {\left[\begin{array}{l}
\mathrm{x}_{\mathrm{g}} \\
\mathrm{y}_{\mathrm{g}} \\
\mathrm{z}_{\mathrm{g}}
\end{array}\right]=\mathrm{T}_{\mathrm{vg}}\left[\begin{array}{l}
\mathrm{x} \\
\mathrm{y} \\
\mathrm{z}
\end{array}\right]=\left[\begin{array}{ccc}
\mathrm{c} \gamma \mathrm{c} \vartheta & \mathrm{c} \gamma \mathrm{s} \vartheta \mathrm{s} \chi-\mathrm{s} \gamma \mathrm{c} \chi & \mathrm{s} \gamma \mathrm{s} \chi+\mathrm{c} \gamma \mathrm{s} \vartheta \mathrm{c} \chi \\
\mathrm{s} \gamma \mathrm{c} \vartheta & \mathrm{c} \gamma \mathrm{c} \chi+\mathrm{s} \gamma \mathrm{s} \vartheta \mathrm{s} \chi & \mathrm{s} \gamma \mathrm{s} \vartheta \mathrm{c} \chi-\mathrm{s} \chi \mathrm{c} \gamma \\
-\mathrm{s} \vartheta & \mathrm{s} \chi \mathrm{c} \vartheta & \mathrm{c} \vartheta \mathrm{c} \chi
\end{array}\right]\left[\begin{array}{l}
\mathrm{x} \\
\mathrm{y} \\
\mathrm{z}
\end{array}\right]} \\
& {\left[\begin{array}{l}
\mathrm{x} \\
\mathrm{y} \\
\mathrm{z}
\end{array}\right]=\mathrm{T}_{\mathrm{bv}}\left[\begin{array}{l}
\mathrm{x}_{1} \\
\mathrm{y}_{1} \\
\mathrm{z}_{1}
\end{array}\right]=\left[\begin{array}{ccc}
\mathrm{c} \beta \mathrm{c} \alpha & -\mathrm{s} \beta & \mathrm{c} \beta \mathrm{s} \alpha \\
\mathrm{s} \beta \mathrm{c} \alpha & \mathrm{c} \beta & \mathrm{s} \beta \mathrm{s} \alpha \\
-\mathrm{s} \alpha & 0 & \mathrm{c} \alpha
\end{array}\right]\left[\begin{array}{l}
\mathrm{x}_{1} \\
\mathrm{y}_{1} \\
\mathrm{z}_{1}
\end{array}\right]}
\end{aligned}
$$

where $\mathrm{X}_{1}$; $\mathrm{Y}_{1}$; and $\mathrm{Z}_{1}\left(\mathrm{X}_{\mathrm{g}}, \mathrm{Y}_{\mathrm{g}}\right.$, and $\left.\mathrm{Z}_{\mathrm{g}}\right)$ are the vectors components along the board (ground) reference axes. The relative attitude between ground and velocity coordinates is represented by the transformation matrix $\mathrm{T}_{\mathrm{vg}}$. In addition, the coordinates' transformation from velocity into body coordinates axes can be carried using the matrix $\mathrm{T}_{\mathrm{bv}}$.

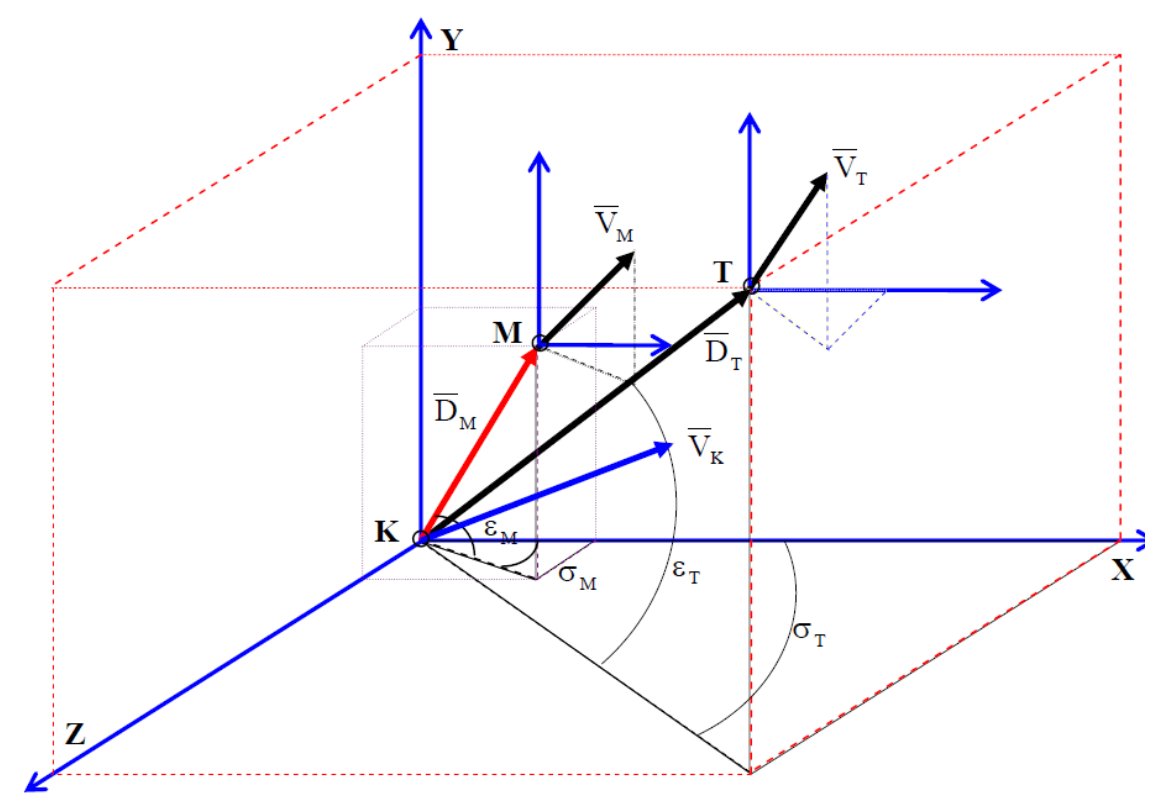

Fig. 3 Geometry of the command guidance 


\subsection{Acting Forces}

The thrust force that act on the missile is assumed to be aligned with the missile longitudinal axis and consequently its components are: $\mathrm{F}_{\mathrm{TXi}}=\mathrm{F}_{\mathrm{T} 1}, \mathrm{~F}_{\mathrm{TYi}}=0, \mathrm{~F}_{\mathrm{TZi}}=0$. Aerodynamic forces have the velocity coordinate system as the mother frame of reference and its components are given $[3,6,11]$ as:

$$
\begin{array}{ll}
\mathrm{F}_{\mathrm{AX}}=-\mathrm{C}_{\mathrm{x}} \mathrm{Sq} & C_{x}=C_{x}^{o}+C_{x}^{\alpha^{2}} \alpha^{2}+C_{x}^{\beta^{2}} \beta \\
\mathrm{F}_{\mathrm{AY}}=-\mathrm{C}_{\mathrm{y}} \mathrm{Sq} & C_{y}=C_{y}^{\beta} \beta \\
\mathrm{F}_{\mathrm{AZ}}=-\mathrm{C}_{\mathrm{z}} \mathrm{S} \mathrm{q} & C_{z}=C_{z}^{\alpha} \alpha
\end{array}
$$

where $\mathrm{F}_{\mathrm{AX}}, \mathrm{F}_{\mathrm{AY}}$, and $\mathrm{F}_{\mathrm{AZ}}$ represent, respectively, the drag, lift, and lateral forces along the velocity axes. $\mathrm{S}$ represents the characteristic area, (q) represents the dynamic pressure and is given by $q=0.5 \rho\left(V_{M}\right)^{2}\left[\mathrm{Kg} / \mathrm{m} / \mathrm{sec}^{2}\right], \rho$ is the air density $\left[\mathrm{kg} / \mathrm{m}^{3}\right], \mathrm{V}_{M}$ is the missile velocity in $[\mathrm{m} / \mathrm{sec}]$, and the aerodynamic coefficients $C_{x}, C_{y}$, and $C_{z}$ are dimension-less. Due to the symmetry of the missile airframe in the pitch and yaw planes, $\mathrm{c}_{\mathrm{y}}^{\circ}=\mathrm{c}_{\mathrm{z}}^{\circ}=0$. The missile weight is determined by the relationship; $\bar{G}=m_{s} \bar{g}$ where $m_{s}$ is the instantaneous total missile mass and $\bar{g}$ is the vector of gravity acceleration.
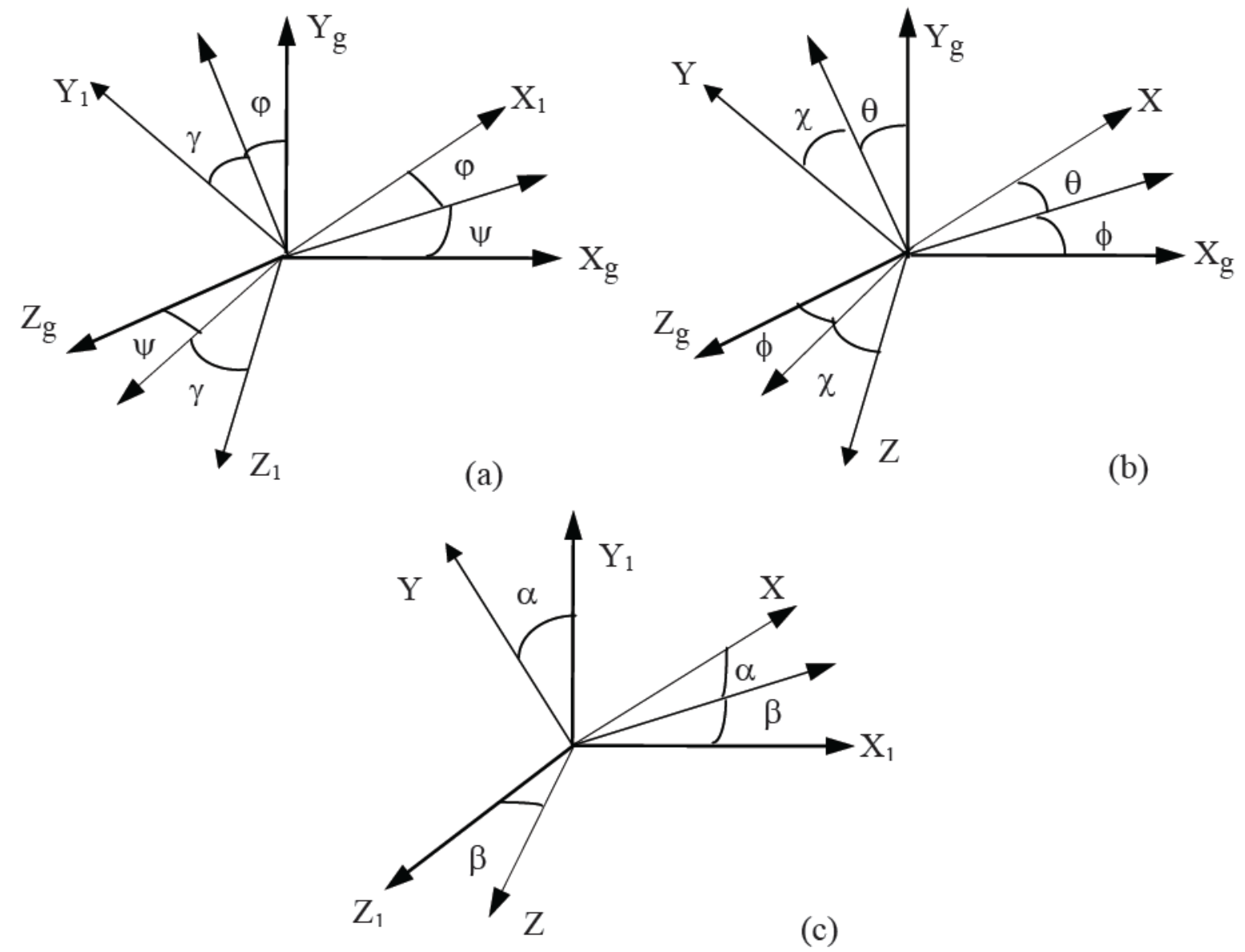

Fig. 4 Relative orientation between:

(a) Reference and board coordinate systems,

(b) Reference and velocity coordinate systems,

(c) Board and velocity coordinate systems. 


\subsection{Acting Moments}

There are three types of moments; thrust moments, the aerodynamic moments and disturbance moments. Thrust moments arise at the time when the thrust does not pass through the missile C.G. and/or does not coincide with the missile longitudinal axis. The aerodynamic moments originate owing to the fact that the resulting aerodynamic forces act at the missile c.p. and do not pass through the missile e.g. It can be given by its components along the board coordinate system axes $[3,6,11]$ as:

$$
\left.\begin{array}{ll}
\mathrm{M}_{\mathrm{AX}_{1}}=\mathrm{m}_{\mathrm{x}_{1}} \mathrm{Sql}_{\mathrm{x}} & \mathrm{m}_{\mathrm{x}_{1}}=\mathrm{m}_{\mathrm{x}_{1}}^{\omega_{\mathrm{x}_{1}}} \omega_{\mathrm{x}_{1}} \\
\mathrm{M}_{\mathrm{AY}_{1}}=\mathrm{m}_{\mathrm{y}_{1}} \mathrm{Sql}_{\mathrm{y}} & \mathrm{m}_{\mathrm{y}_{1}}=\mathrm{m}_{\mathrm{y}_{1}}^{\omega_{\mathrm{y}_{1}}} \omega_{\mathrm{y}_{1}}+\mathrm{m}_{\mathrm{y}_{1}}^{\alpha} \alpha \\
\mathrm{M}_{\mathrm{Az}_{1}}=\mathrm{m}_{\mathrm{z}_{1}} \mathrm{Sql}_{\mathrm{z}} & \mathrm{m}_{\mathrm{z}_{1}}=\mathrm{m}_{\mathrm{z}_{1}}^{\omega_{\mathrm{z}_{1}}} \omega_{\mathrm{z}_{1}}+\mathrm{m}_{\mathrm{z}_{1}}^{\beta} \beta
\end{array}\right\} \text { (X-form missile) }
$$

where: $l_{x}, I_{y}, I_{z}$. are the characteristic linear dimensions of missile, $\mathrm{S}$ is the characteristic area of missile, and $m_{x_{1}}, m_{y_{1}}$, and $m_{z_{1}}$ are dimensionless aerodynamic coefficients, and $\omega_{x_{1}}, \omega_{y_{1}}$, and $\omega_{z_{1}}$ are the airframe-turn rates alone board coordinate axes as shown in Fig. 3.

\subsection{Equations of Motion}

The missile motion is determined by the force vector equation $[6,11]$ :

$$
\sum \overline{\mathrm{F}}=\mathrm{m} \overline{\mathrm{J}}=\mathrm{m} \frac{\mathrm{d}\left(\overline{\mathrm{V}}_{\mathrm{M}}\right)}{\mathrm{dt}}=\mathrm{m} \dot{\mathrm{V}}_{\mathrm{M}} \hat{\mathrm{V}}_{\mathrm{M}}+\mathrm{m}\left(\bar{\Omega} \otimes \overline{\mathrm{V}}_{\mathrm{M}}\right)
$$

where $\mathrm{m}$ is the missile mass, $\bar{J}$ is the acceleration of missile, and $\bar{F}$ is the external force acting on the missile, $\Omega$ is the angular velocity of VCS w.r.t GCS whose components in VCS are $\Omega_{\mathrm{x}}, \Omega_{\mathrm{y}}$ and $\Omega_{\mathrm{z}}$. as shown in Fig 2. The components of angular rates of Euler's angles $\{\dot{\gamma}, \dot{\vartheta}, \dot{\chi}\}$ and the algebraic manipulation yield the dynamics of missile e.g. motion:

$$
\begin{array}{ll}
\dot{\vartheta}=\Omega_{y} \cos \chi-\Omega_{z} \sin \chi & \\
\dot{\gamma} \cos \vartheta=\Omega_{y} \sin \chi+\Omega_{z} \cos \chi & \\
\dot{\chi}=\Omega_{x}+\tan \vartheta\left(\Omega_{z} \cos \chi+\Omega_{y} \sin \chi\right) & \\
\dot{\mathrm{v}}_{\mathrm{M}}=\mathrm{g}_{\mathrm{x}}+\Phi_{\mathrm{x}}-\frac{\mathrm{C}_{\mathrm{x}} \mathrm{sq}}{\mathrm{m}} & n_{\alpha}=\frac{1}{m v_{M}}\left(C_{z}^{\alpha} s q\right) \\
\dot{\vartheta}=\mathrm{N} \cos \chi-\mathrm{K} \sin \chi-\frac{\mathrm{g} \cos \vartheta}{\mathrm{v}_{\mathrm{M}}} & k_{\circ}=\frac{1}{m v_{M}}\left(F_{T x_{1}} s \beta c \alpha+F_{T y_{1}} c \beta+F_{T z_{1}} s \beta s \alpha\right) \\
\dot{\gamma} \cos \vartheta=\mathrm{N} \sin \chi+\mathrm{K} \cos \chi & \\
\Phi_{x}=\left(F_{T x_{1}} c \beta c \alpha-F_{T y_{1}} s \beta+F_{T z_{1}} c \beta s \alpha\right) / m & \\
n_{\circ}=-\frac{1}{m v_{M}}\left(-F_{T x_{1}} s \alpha+F_{T z_{1}} c \alpha\right) & \\
K=k_{\circ}+k_{\beta} \beta & \\
k_{\beta}=-\frac{1}{m v_{M}}\left(C_{y}^{\beta} s q\right) &
\end{array}
$$

The external moments acting on a body equal to the time rate of change of its moment of momentum (angular momentum) [6.11]: $\sum \overline{\mathrm{M}}=\mathrm{d} \overline{\mathrm{H}} / \mathrm{dt}$. Due to symmetry of missile configuration, the products of inertia are neglected $[6,11]$ and the equations of missile rotation around its e.g. are obtained as follows: 


$$
\begin{aligned}
& \dot{\theta}=\omega_{y_{1}} \cos \phi-\omega_{z_{1}} \sin \phi \\
& \dot{\psi}=\left(\omega_{z_{1}} \cos \phi+\omega_{y_{1}} \sin \phi\right) / \cos \theta \\
& \dot{\phi}=\omega_{x_{1}}+\left(\omega_{z_{1}} \cos \phi+\omega_{y_{1}} \sin \phi\right) \tan \theta \\
& \dot{\omega}_{x_{1}}=M_{x_{1}} / I_{x x}+\left(I_{y y}-I_{z z}\right) \omega_{y_{1}} \omega_{z_{1}} / I_{x x} \\
& \dot{\omega}_{y_{1}}=M_{y_{1}} / I_{y y}+\left(I_{z z}-I_{x x}\right) \omega_{x_{1}} \omega_{z_{1}} / I_{y y} \\
& \dot{\omega}_{z_{1}}=M_{z_{1}} / I_{z z}+\left(I_{x x}-I_{y y}\right) \omega_{y_{1}} \omega_{x_{1}} / I_{z z}
\end{aligned}
$$

where $\mathrm{I}_{\mathrm{xx}}, \mathrm{I}_{\mathrm{yy}}$, and $\mathrm{I}_{\mathrm{zz}}$ are moments of inertia components along the board coordinate axes.

Geometrical Relations: The relative attitude between reference frames can be described by considering the Euler's angles and manipulating the transformation equations to yield:

$$
\begin{aligned}
& \theta=\vartheta+\beta \sin \chi+\alpha \cos \chi \\
& \phi=\psi+\alpha \tan \vartheta \sin \chi-\beta \tan \vartheta \cos \chi \\
& \psi=\gamma+((\alpha \sin \chi-\beta \cos \chi) / \cos \vartheta)
\end{aligned}
$$

\section{6DOF Flight Simulation}

A flight simulation model is designed in a modular structure to obtain the flight trajectory of the missile with programs built within the MATLAB environments. The flowchart that clarifies the flow of data among the various modules is given in Fig. 5. The simulation model can be broken down into the following major parts: missile-target geometry, guidance, control, thrust, force-moments, aerodynamics, and missile [4,5]. The module denoted by CRB1 represents the transformation between the reference and the board coordinate systems. The output velocity corrupted with the wind is applied to the aerodynamic module, which calculates the aerodynamic forces and moments. The thrust module computes the thrust force components along the missile axes according to the actuator deflection angles $8 p$ and $8 y$ in pitch and yaw planes, respectively. The deflection angles are generated in the actuator module which stimulated by the input voltages generated from the autopilot module. The autopilot calculates these voltages by comparing the guidance commands, which represent the desired missile heading and the actual missile heading. The difference between both is processed in the autopilot electronics to produce the desired actuator deflection. The solution of the missile dynamical equations of motion is carried out numerically in the vehicle dynamics module where Rung-Kutta 4 method is employed. The outputs of the missile dynamics module are the missile linear and angular acceleration components obtained in the board coordinate system. Through the transformation module, the missile velocity and turn rates expressed in the reference coordinate system are obtained. Integrating these velocities yields the missile instantaneous position. Inside the geometry module the missile instantaneous position is compared with the target position and the relative error is obtained. The guidance module generates guidance commands in addition to the pre-programmed commands which applied to the missile autopilot just after launch. The purpose of these commands is to gather the missile to the target line of sight with no intervention from the guidance commands in the initial flight period.

The simulation is conducted with nominal and perturbed values and depicted with the reference as shown in Fig. 6. This Figure reveals that the established flight simulation which had programmed within the MATLAB environments yield trajectories that are nearly consistent with reference trajectories. The obtained results yield the appropriate and somehow accurate model that can be used for the guidance and control design. 


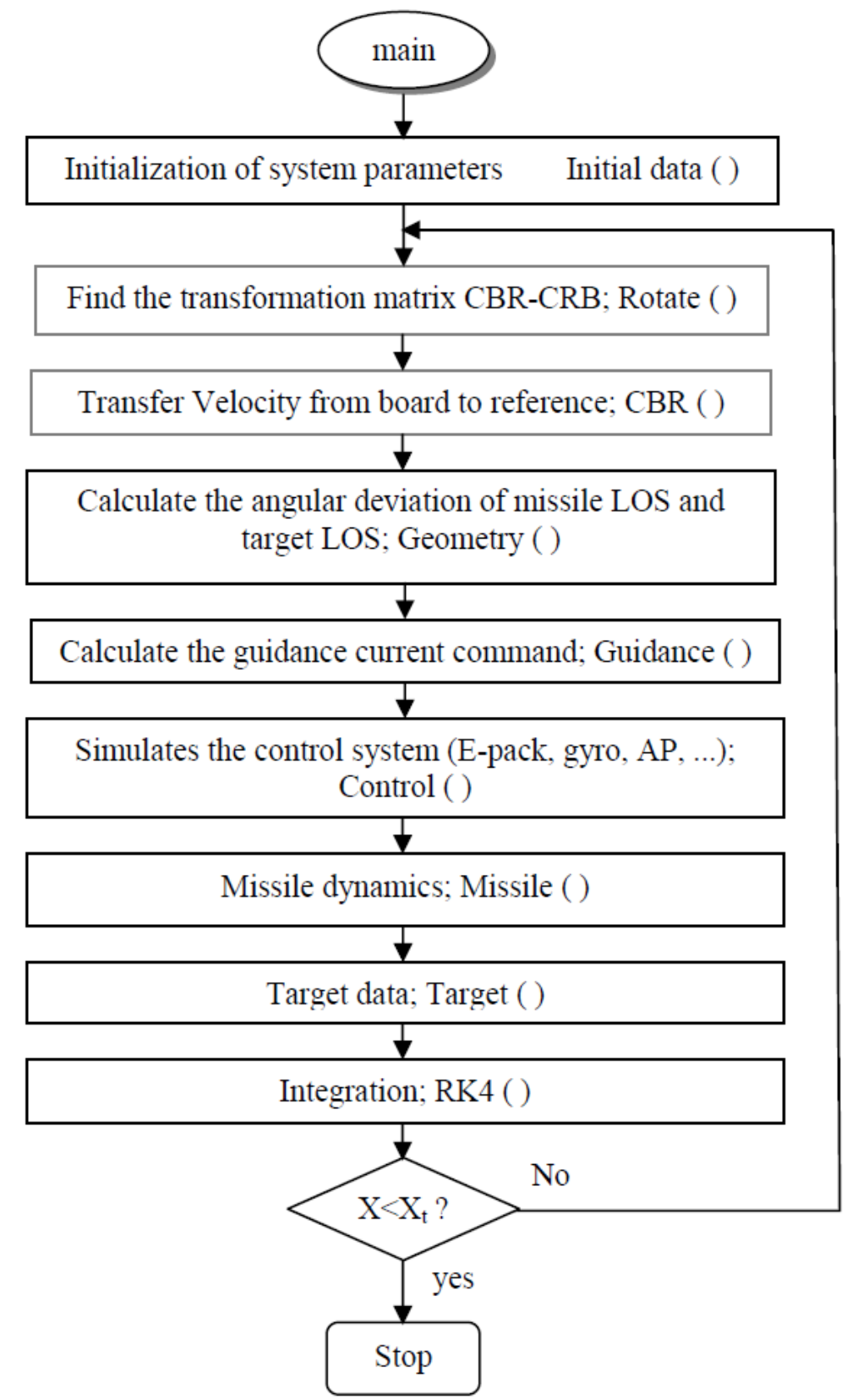

Fig. 5 Flowchart of the 6DOF flight simulation model

\section{Autopilot Design and Analysis}

The ever-increasing development of tanks capabilities necessitates the design of accurate control and guidance system for an antitank missile in presence of disturbance, measurement noise, and un-modeled dynamics. To achieve this objective, the above sections of the paper extracted a nonlinear mathematical model representing the dynamical behavior of the underlying missile for different flight phases. The system uncertainties included thrust variation due to different causes, variation in aerodynamic coefficients and parameters, wind velocity in different directions and different trim conditions. To overcome different sources of uncertainty, robust control is used to design the autopilot such that the system is stable with the ability to overcome un-modeled dynamics, to reject the disturbances and minimize the 

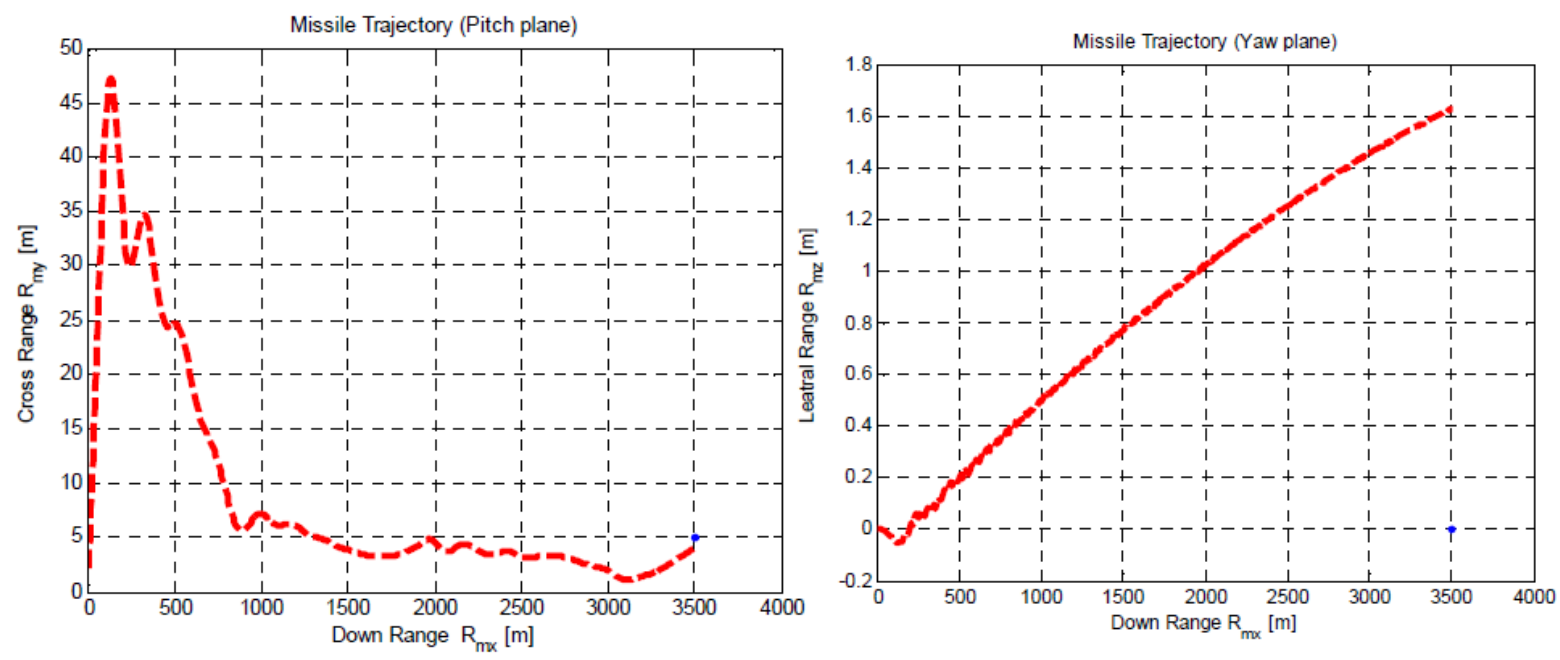

Fig. 6: Missile flight path in (a) pitch (b) yaw planes
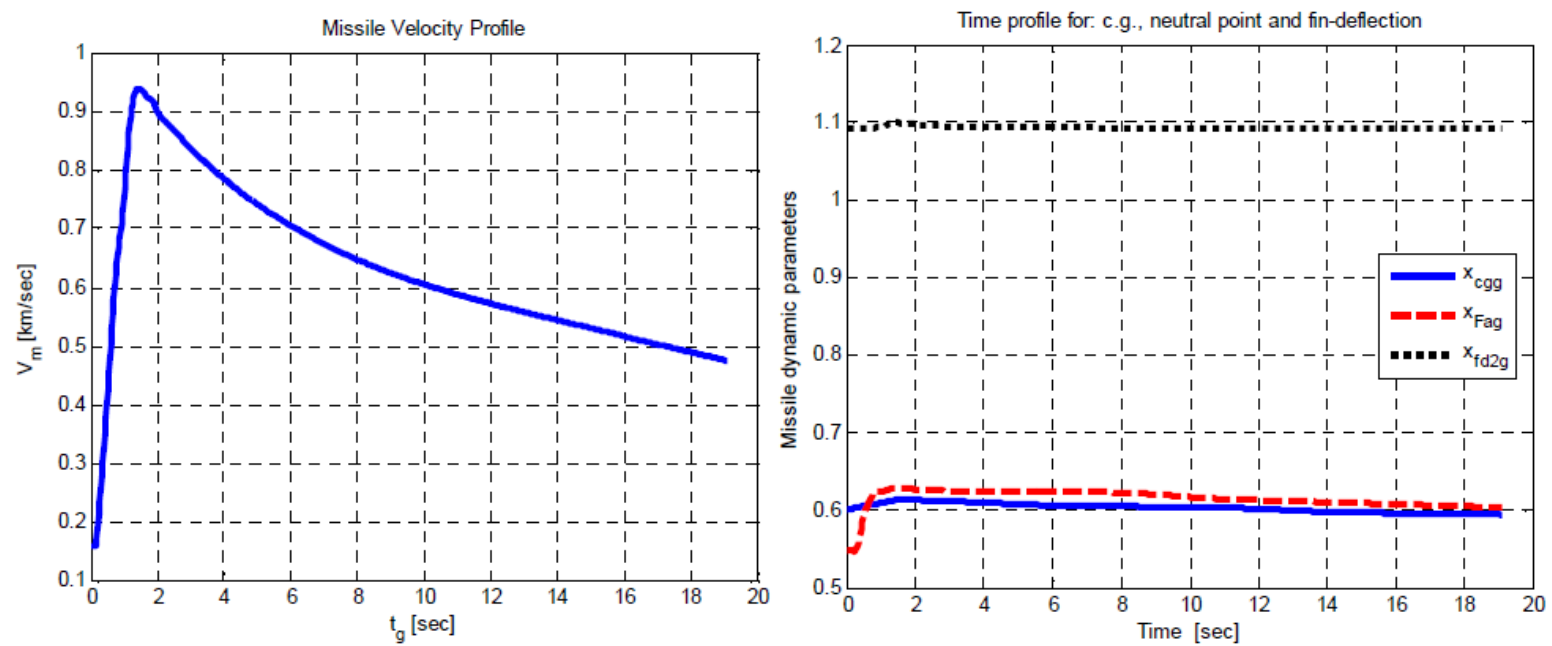

Fig. 6: (c) Velocity profile (d) Static margin variation

effects of measurement noises overall the missile flight envelope. The performance specifications include overshoot, speed of response, steady state error, and system stability in addition to flight paths with different engagement scenarios. To overcome the effects due to uncertainties and achieve the performance requirements this section is devoted to design the autopilot for the underlying command to line-of-sight (CLOS) system using the classical and $\mathrm{H}_{\infty}$, -robust with evaluation. This control system is said to be robust when it maintains a satisfactory level of stability and performance over a range of plant parameters, disturbances and noises [7]. Thus, the objective is to investigate the robustness of the designed autopilot against uncertainties due to different sources. The designed controller is implemented within the missile control system and should be insensitive to model uncertainties and be able to suppress disturbances and noise over the whole envelope of operation to prove its robustness.

A feedback-control system must satisfy certain performance specifications and it must tolerate model uncertainties. The feedback control system has three components: the plant, sensors to measure the plant outputs $y(t)$, and a controller to generate the plant's input or control signal $u(t)[5]$ according to the tracking error $e(t)$, Fig. 7. 


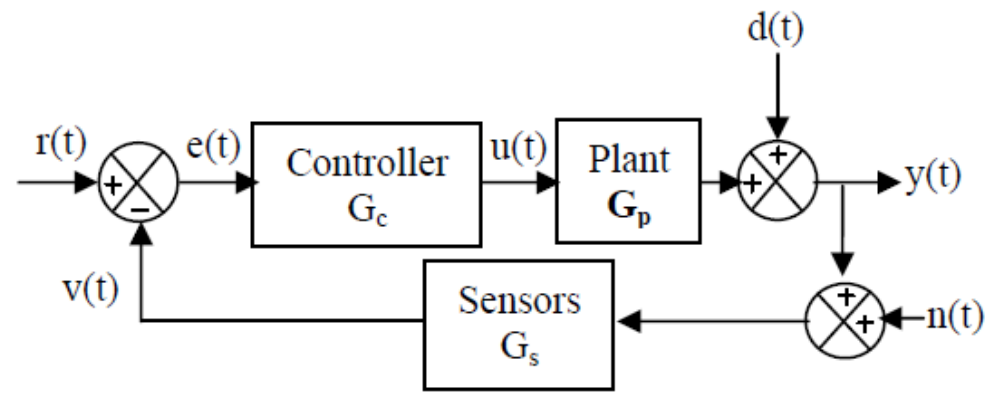

Fig. 7 Feedback Control

\subsection{Pitch Airframe Dynamics}

Towards the autopilot design, the guidance equations have to be linearized for extracting the necessary airframe transfer function or state space models that can be used for autopilot design and analysis. That is, consider equations which describe equations of motion for the intended guided missile, with the assumptions [4,6,9,15]: planer motion, constant velocity, small firing angles $(\alpha, \beta)$. and zero thrust misalignment. The obtained linearized equations describing dynamics of the guided missile c.g motion, rotation around c.g. and geometrical relations can be summarized as follows:

$$
\begin{array}{lll}
\ddot{\varphi}=\mathrm{a}_{\dot{\varphi}} \dot{\varphi}+\mathrm{a}_{\alpha} \alpha+\mathrm{a}_{\delta} \delta_{\mathrm{p}} & \mathrm{a}_{\dot{\varphi}}=\mathrm{m}_{\mathrm{z}_{1}}^{\dot{\varphi}} \mathrm{sq} \ell / \mathrm{I}_{\mathrm{zz}} & \mathrm{n}_{\delta_{\mathrm{p}}}=\frac{\mathrm{F}_{\mathrm{T}_{1}}}{\mathrm{mv}_{\mathrm{M}}} \\
\dot{\theta}=\mathrm{n}_{\alpha} \alpha+\mathrm{n}_{\delta_{\mathrm{p}} \delta} \delta_{\mathrm{p}} & \mathrm{a}_{\alpha}=\mathrm{m}_{\mathrm{z}_{1}}^{\alpha} \mathrm{sq} \ell / \mathrm{I}_{\mathrm{zz}} & \mathrm{n}_{\alpha}=\frac{1}{\mathrm{mv}_{\mathrm{M}}}\left(\mathrm{C}_{\mathrm{z}}^{\alpha} \mathrm{sq}+\mathrm{F}_{\mathrm{T}_{1}}\right)
\end{array}
$$

Applying the Laplace transform and algebraic manipulation to $\mathrm{Eq}^{\mathrm{ns}} 12$ yield the obtained airframe transfer functions as:

$$
\begin{aligned}
& \frac{\dot{\varphi}(\mathrm{s})}{\delta_{\mathrm{p}}(\mathrm{s})}=\frac{\mathrm{a}_{\delta} \mathrm{s}+\left(\mathrm{a}_{\delta} \mathrm{n}_{\alpha}-\mathrm{a}_{\alpha} \mathrm{n}_{\delta}\right)}{\mathrm{s}^{2}+\left(\mathrm{n}_{\alpha}-\mathrm{a}_{\dot{\phi}}\right) \mathrm{s}-\left(\mathrm{a}_{\dot{\phi}} \mathrm{n}_{\alpha}-\mathrm{a}_{\alpha}\right)} \\
& \frac{\alpha(\mathrm{s})}{\delta_{\mathrm{p}}(\mathrm{s})}=\frac{-\mathrm{n}_{\delta_{\mathrm{p}}} \mathrm{s}+\left(\mathrm{a}_{\delta}+\mathrm{a}_{\dot{\phi}} \mathrm{n}_{\delta_{\mathrm{p}}}\right)}{\mathrm{s}^{2}-\left(\mathrm{a}_{\dot{\phi}}-\mathrm{n}_{\alpha}\right) \mathrm{s}-\left(\mathrm{a}_{\dot{\phi}} \mathrm{n}_{\alpha}+\mathrm{a}_{\alpha}\right)} \\
& \frac{\dot{\theta}(\mathrm{s})}{\delta_{\mathrm{p}}(\mathrm{s})}=\frac{\mathrm{n}_{\delta_{\mathrm{p}}} \mathrm{s}^{2}-\mathrm{n}_{\delta_{\mathrm{p}}} \mathrm{a}_{\dot{\phi}} \mathrm{s}+\left(\mathrm{a}_{\delta} \mathrm{n}_{\alpha}-\mathrm{a}_{\alpha} \mathrm{n}_{\delta}\right)}{\mathrm{s}^{2}+\left(\mathrm{n}_{\alpha}-\mathrm{a}_{\dot{\phi}}\right) \mathrm{s}-\left(\mathrm{a}_{\dot{\phi}} \mathrm{n}_{\alpha}-\mathrm{a}_{\alpha}\right)} \\
& \frac{\mathrm{J}_{z}(\mathrm{~s})}{\delta_{\mathrm{jp}}(\mathrm{s})}=\frac{\mathrm{V}_{\mathrm{M}}\left\{\mathrm{n}_{\delta_{\mathrm{p}}} \mathrm{s}^{2}-\mathrm{n}_{\delta_{\mathrm{p}}} \mathrm{a}_{\dot{\phi}} \mathrm{s}+\left(\mathrm{a}_{\delta} \mathrm{n}_{\alpha}-\mathrm{a}_{\alpha} \mathrm{n}_{\delta}\right)\right\}}{\mathrm{s}^{2}+\left(\mathrm{n}_{\alpha}-\mathrm{a}_{\dot{\varphi}}\right) \mathrm{s}-\left(\mathrm{a}_{\dot{\phi}} \mathrm{n}_{\alpha}-\mathrm{a}_{\alpha}\right)}
\end{aligned}
$$

Body Rate Transfer Function

Angle of Attack Transfer Function

Flight Path Transfer Function

Normal Acceleration Transfer Function

The pitch control system structure is shown in Fig. 8, where the gyro is a rate gyro used to measure the body angular rate. The airframe transfer function $\left(\dot{\varphi} / \delta_{P}\right)$ expressed in $\mathrm{Eq}^{\mathrm{nn}} 10$ is obtained via conducting the $6 \mathrm{DOF}$ simulation with target at distance 2500 [m] and considering 10 operating points during the flight envelope. The extracted airframe transfer function has the form $\frac{\dot{\varphi}(s)}{\delta_{P}(s)}=\frac{a_{1} S+a_{2}}{S^{2}+b_{1} S+b_{2} s}$.

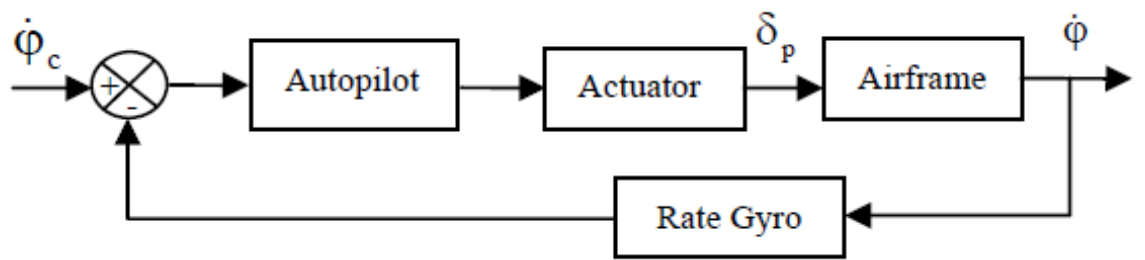

Fig. 8 Pitch control system 
The parameters of this transfer function are listed in Table(l) and the frequency response of the airframe at different operating conditions is shown in Fig. 9 which clarifies that the max gain variation is $6.6[\mathrm{~dB}]$ while the maximum phase variation is $24^{\circ}$.

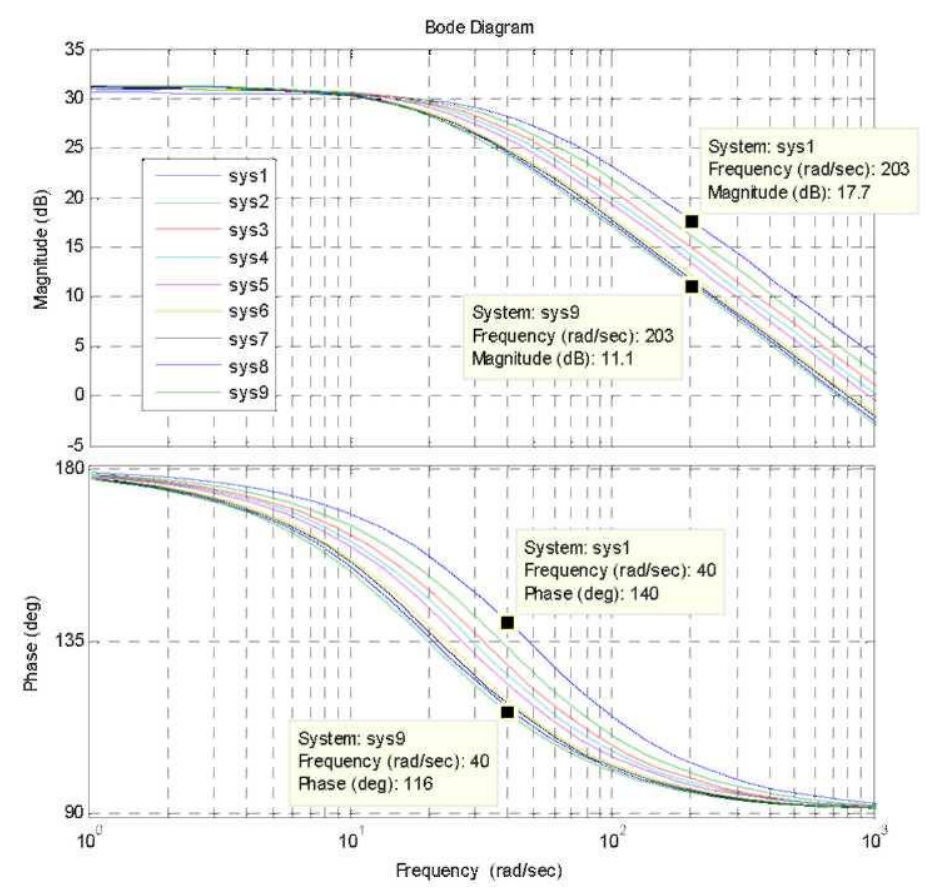

Fig. 9 Airframe frequency response at different trim conditions

Table 1 The body rate transfer dynamics of pitch plane at different trim conditions

\begin{tabular}{c|c|c|c|c|c}
\hline \hline Trim & $\mathrm{t}_{\mathrm{f}}[\mathrm{sec}]$ & $\mathrm{a}_{1}$ & $\mathrm{a}_{2} \times 10^{4}$ & $\mathrm{~b}_{1} \times 10^{5}$ & $\mathrm{~b}_{2} \times 10^{6}$ \\
\hline 1 & 0.15 & -42.087 & -3.0629 & 0.0071 & 0.00051 \\
\hline 2 & 1.5 & -1670 & -42708 & 2.5675 & 12.826 \\
\hline 3 & 2.4 & -1440 & -28083 & 1.9531 & 8.1041 \\
\hline 4 & 3.6 & -1220 & -18159 & 1.4840 & 5.1307 \\
\hline 5 & 4.8 & -1070 & -12754 & 1.1897 & 3.5875 \\
\hline 6 & 5.7 & -983.41 & -10123 & 1.0307 & 2.8488 \\
\hline 7 & 6.6 & -907.8 & -8203.7 & 0.90493 & 2.3023 \\
\hline 8 & 7.5 & -844.4 & -6784.4 & 0.80453 & 1.897 \\
\hline 9 & 8.4 & -790.6 & -5706.5 & 0.7227 & 1.5712 \\
\hline 10 & 9.15 & -751.5 & -4993 & 0.66309 & 1.3672 \\
\hline \hline
\end{tabular}

\subsection{Classical Autopilot Synthesis}

\subsubsection{PID controller tuning}

The PID controller is still the most used control system in industries [23], because of its simplicity, ease of implementation and availability of tuning tools and calibration. There are many methods for tuning a PID controller among them are the analytical tuning off-line methods which may be classified into two main families depending on the nature of the model. The first family, organized by Ziegler and Nichols (1942), which proposed a set of analytical formulas to determine the parameters of PID controllers based on the first-order 
plus dead time process model. This model is identified by step response (Ziegler-Nichols first method) or by frequency response (Ziegler-Nichols second method). Because of its simplicity, the Ziegler-Nichols method is still widely used despite the fact that they do not address the robustness and the performance of the system. Automatic tuning of PID parameters has also been proposed by Astrom and Hagghmd [2, 3] that extended the ZieglerNichols (first and second) methods to the automatic tuning of the PID controller. The autotuning technique is obtained by combining the methods for determining the process dynamics with the method for computing the PID parameters. The PID tuning methods are utilized with the pitch transfer functions from which the selected controller parameters are listed in Table (2).

Table 2 Classical controller parameters

\begin{tabular}{c|c|c|c}
\hline \hline Parameter & PD & PI & PID \\
\hline $\mathrm{K}_{\mathrm{P}}$ & -326.332 & -0.4859 & -1.8357 \\
\hline $\mathrm{K}_{\mathrm{D}}$ & -2.7974 & - & -0.048795 \\
\hline $\mathrm{K}$, & - & -0.1288 & -0.90368 \\
\hline Rise time [sec] & 0.000526 & 0.087 & 0.0234 \\
\hline Settling time [sec] & 0.00437 & 0.305 & 0.0758 \\
\hline O.S. [XI & 10.4 & 9.38 & 9.05 \\
\hline Gain margin [dB] & On & oo & oo \\
\hline Phase margin [deg] & 60 & 60.3 & 60 \\
\hline
\end{tabular}

\subsubsection{Controller performance evaluation}

Step Response: Let us consider the $\mathbf{6}^{\text {th }}$ pitch airframe transfer function as a nominal airframe which has a moderate frequency response compared with the remainder trim points. Using the tuned classical controllers (PD, PI, PID) of Table (2), the step response for the pitch autopilot is shown in Fig. 10, where the response parameters are given in Table (2). The results clarify that the PD yields faster response with little increase in overshoot.

Noise Attenuation: Applying white Gaussian noise to the sensor output with noise to signal ratio (NSR) 7\%. the obtained control effort is shown $\mathrm{m}$ Fig. 11. winch clarify that PD controller is more sensitive to additive noise compared to others.

Disturbance Rejection: An impulse disturbance is applied at the system output; according to which they obtained step response of closed loop system is shown m Fig. 12. This figure which clarifies that the convergence using PD after applying a disturbance is the best compared to other controllers as it rejects $50 \%$ within $0.01 \mathrm{sec}$ and reject $95 \%$ within $0.04 \mathrm{sec}$. The PI controller rejects $50 \%$ within $0.09 \mathrm{sec}$ and reject $95 \%$ within $0.35 \mathrm{sec}$ while the PID controller rejects $50 \%$ within $0.03 \mathrm{sec}$ and reject $95 \%$ within $0.15 \mathrm{sec}$.

Unmodeled Dynamics: The three designed controllers are implemented at the different operating points from which the obtained results clarify that the controller obtained taking the $6^{\text {th }}, 3^{\text {th }}$ and $9^{\text {th }}$ operating points as a nominal transfer function is not stable against all unmodeled dynamics for the original autopilot while it is stable against all unmodeled dynamics for the designed autopilot as shown in Fig. 13. 


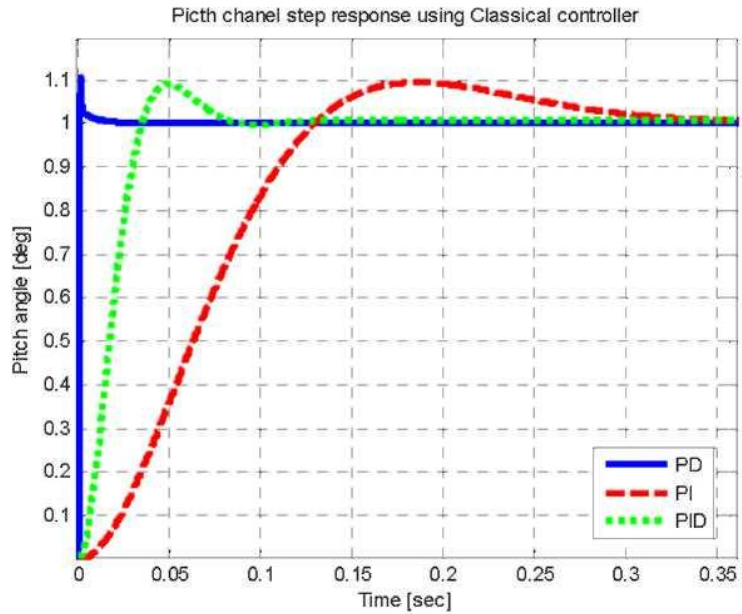

Fig. 10 Classical Pitch channel step response

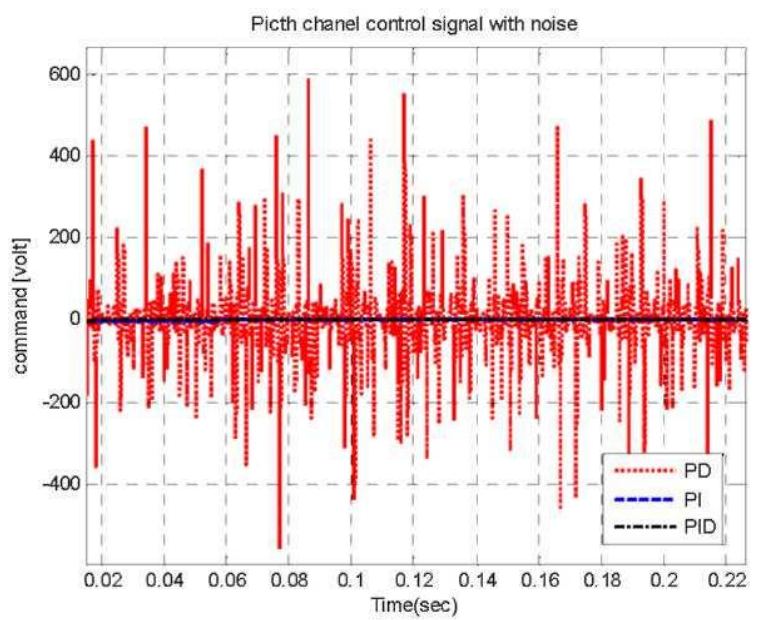

Fig. 11 Classical control effort with noise

\subsubsection{Flight path analysis}

Guidance system evaluation represents one of the major tasks following the autopilot design. This evaluation is carried out by conducting the 6DOF simulation using the autopilot with different engagement scenarios. Some of these scenarios are shown in Fig. 14, which compare between the systems with proportional and the obtained PD controllers. Applying the proportional controller, the missile can hit the ground but with PD controller the missile hits the target as shown in Fig. 15 by less miss-distance. On the other hand, the missile attack the target but with large miss-distance using proportional controller while by applying the PD controller this miss-distance is reduced to become very small. Applying the PI and PID controller the miss-distance is very high which is not accepted and the system is not stable.

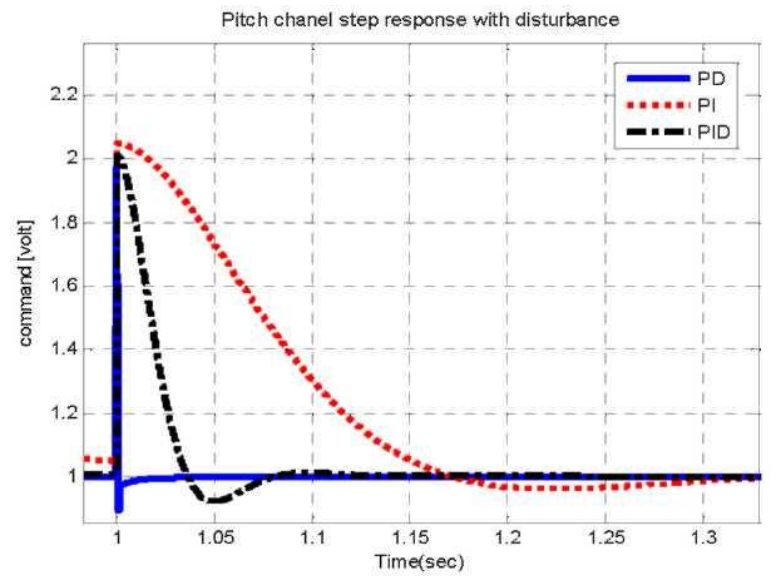

Fig. 12 Classical pitch disturbance response

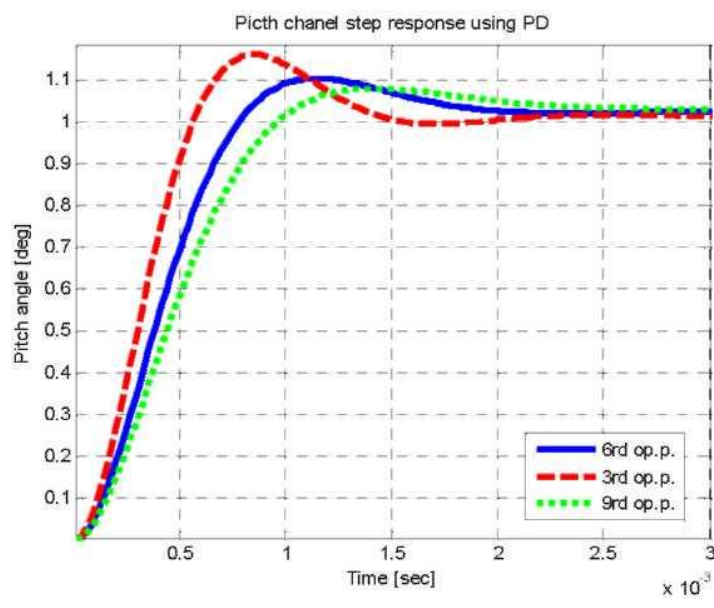

Fig. 13 Step response using PD 

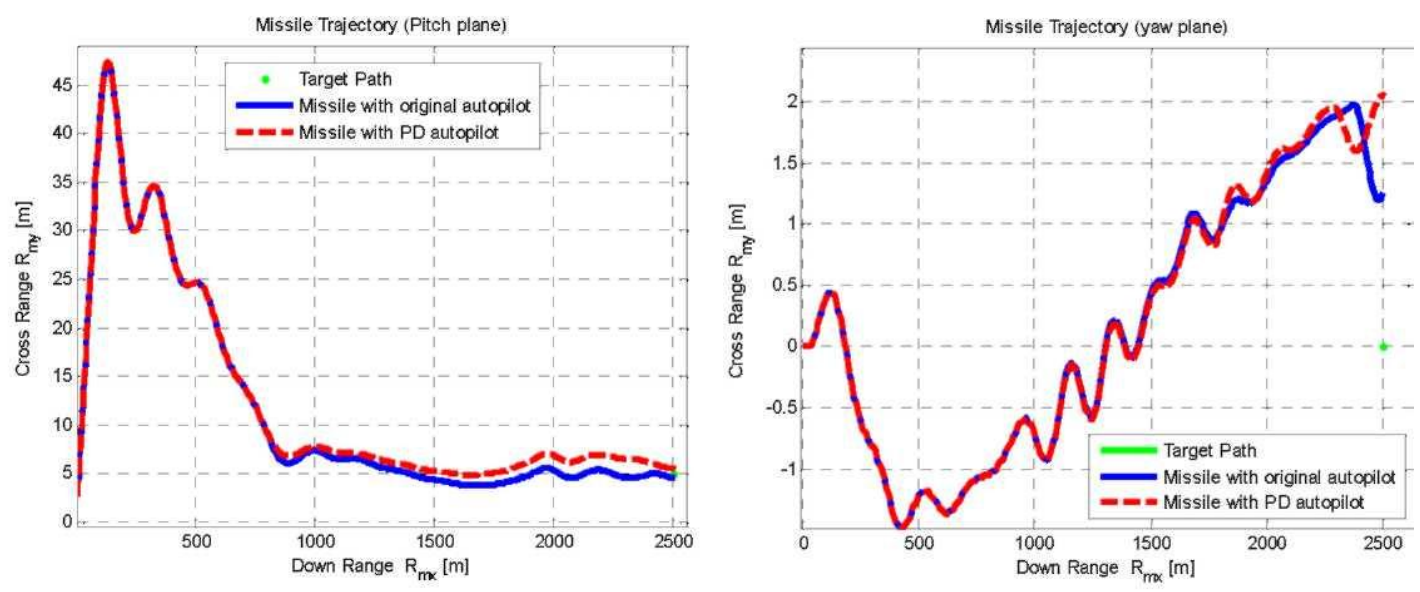

Fig. 14 Flight path; Scenario-3
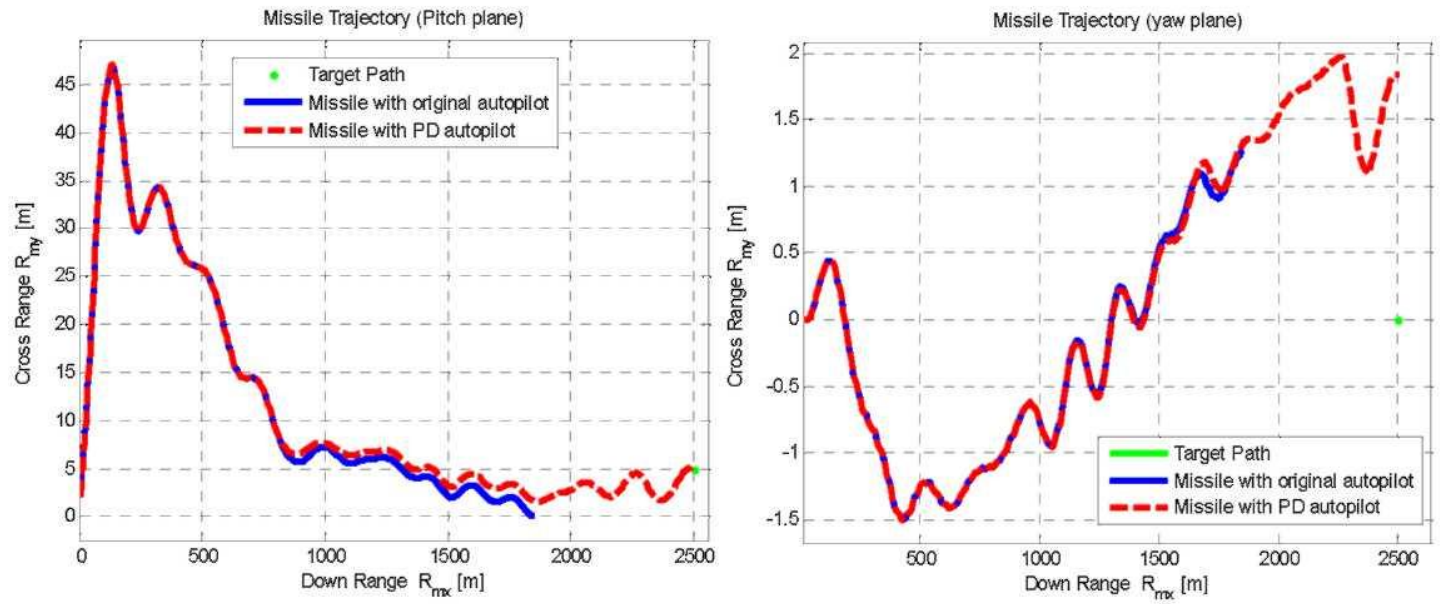

Fig. 15 Flight path; Scenario-8

The classical pitch channel controller is designed and evaluated against unmodeled dynamics, measurement noise, disturbances and flight path nonlinearzies. The obtained results clarify that the designed PD achieved less miss-distance and less control signal.

\subsection{Robust Autopilot Synthesis}

\subsection{1 $\mathrm{H}_{\infty}$ robust control}

One way to describe the performance of a control system is in terms of the size of certain signals of interest. For example, the performance of a tracking system could be measured by the size of the error signal. There are several ways of defining a signal's size (i.e. several norms for signals), among these norms is the $\infty$-Norm. The $\infty$-Norm of a signal $\mathrm{u}(\mathrm{t})$ is the least upper bound of its absolute value $\|\mathrm{u}\|_{\infty}:=\sup |u(\mathrm{t})|$. There are several robust techniques, among them is the $\mathrm{H}_{\infty}$ where a quantitative measure for the size of the system uncertainty is considered. The infinity norm of the transfer function relating the input to the output is the worst-case gain between the two, where both the input and output are measured either by their energy or peak value [4]. Other measures of gain can also characterize worst-case amplifications, but in ways which seem to be less useful in practice.

The set of all stable transfer functions whose infinity norms are finite forms a Hardy space [2, $3,4]$ and denoted by $\|\mathrm{H}\|_{\infty}$. Moreover, it is the approach which gives much of recent robust control theory its name. The theory is of great interest because it gives solutions to realistic 
robust control problems known as $\|\mathrm{H}\|_{\infty}$ optimization problems. The methods of $H_{\infty}$ synthesis are powerful tools for designing robust feedback control systems to achieve singular value loop shaping specifications. The standard $H_{\infty}$ control problem is sometimes also called the $H_{\infty}$ small gain problem. The small-gain theorem states that if a feedback loop consists of stable systems, and the product of all their gains is smaller than one, then the feedback loop is stable $[1,7,19]$. That is, assuming that the blocks $P$ and $C$ in Fig. 16 are stable, then the closed loop system remains stable if $\left\|T_{y_{1} u_{1}}\right\|<1$, where $\left\|T_{y_{1} u_{1}}\right\|$ is the feedback closed loop transfer function. The small gain problem shows a general setup, and the problem of making $\left\|T_{y_{1} u_{1}}\right\|_{\infty} \leq 1$ is also called the small-gain problem. For $H_{\infty}$ design problem, the state-space model of an augmented plant $\mathrm{P}(\mathrm{s})$ with weighting functions $\mathrm{W}_{\mathrm{p}}(\mathrm{s}), \mathrm{W}_{\mathrm{u}}(\mathrm{s})$, and $\mathrm{W}_{\mathrm{t}}(\mathrm{s})$ which penalize the error signal, control signal and output signal, respectively, is formulated as shown in Fig. 17 so that the closed-loop transfer function matrix is the weighted mixed sensitivity; $\mathbf{T}_{\mathbf{y}_{1} \mathbf{u}_{\mathbf{1}}}=\left[\begin{array}{lll}\mathbf{W}_{\mathbf{p}} \mathbf{S} & \mathbf{W}_{\mathbf{u}} \mathbf{M} & \mathbf{W}_{\mathbf{t}} \mathbf{T}\end{array}\right]^{\mathbf{T}}$. In practice, it is usually not necessary to obtain a true optimal controller, but it is often simpler to find a sub-optimal controller. Suppose that $\gamma_{\text {min }}$ is the minimum value of $\left\|F_{i}(P, C)\right\|_{\infty}$ over all possible stabilizing controllers $\mathrm{C}$. Then, the $\mathrm{H}_{\infty}$ sub-optimal control problem is: Given a $\gamma>\gamma_{\min }$, find all stabilizing controllers such that $\left\|F_{i}(P, C)\right\|_{\infty}<\gamma$. This problem can be solved efficiently using the algorithm of Doyle et al. (1989), by reducing $\gamma$ iteratively to yield the optimal solution [5].

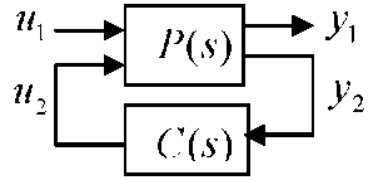

Fig. 16 Small Gain Problem

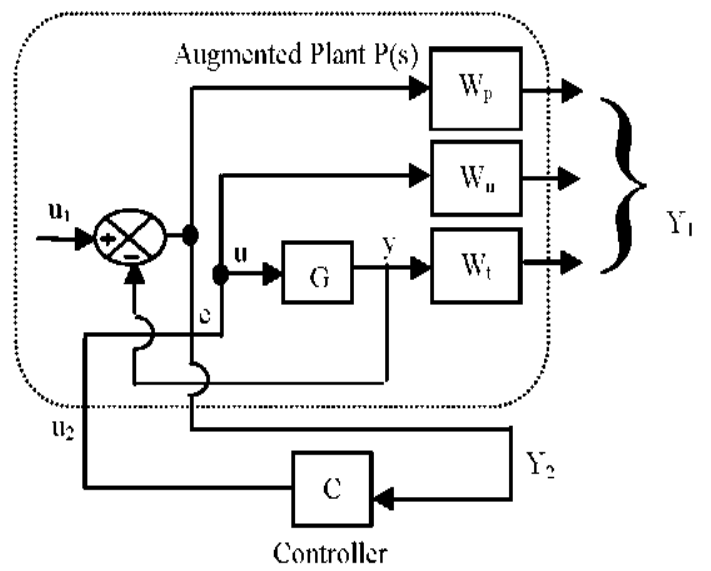

Fig. 17 Augmented Plant .P(s)

\subsubsection{Robust autopilot design trials}

A robust controller is designed using the following weights:

$$
\begin{aligned}
& \mathrm{W}_{\mathrm{p} 1}=\frac{0.0055 \mathrm{~S}+24}{0.221 \mathrm{~S}+0.00411}, \quad \mathrm{~W}_{\mathrm{t} 1}=\frac{0.009 \mathrm{~S}+80}{4.1 \mathrm{~S}+2210}, W_{u 1}=0 \\
& W_{p 2}=\frac{0.0055 S+42}{0.221 S+0.00411}, \quad \mathrm{~W}_{12}=\frac{0.009 \mathrm{~S}+85}{5.8 \mathrm{~S}+2210}, W_{u 2}=0 \\
& W_{p, 3}=\frac{0.0055 S+25}{0.221 S+0.00411}, \quad W_{13}=\frac{0.009 S+82}{9.5 S+2210}, W_{u 3}=0 \\
& \mathrm{~W}_{\mathrm{p} 4}=\frac{0.0055 \mathrm{~S}+24.9}{0.221 \mathrm{~S}+0.00411}, \quad \mathrm{~W}_{\mathrm{t} 4}=\frac{0.009 \mathrm{~S}+81.5}{8 \mathrm{~S}+2210}, W_{u 4}=0
\end{aligned}
$$

The obtained controllers are of high order that can be reduced using model-order reduction techniques to yield the following; 


$$
\begin{aligned}
& \mathrm{C} 1=\frac{-1.284 \mathrm{e} 009 \mathrm{~s}^{4}-1.33 \mathrm{e} 014 \mathrm{~s}^{3}-7.5 \mathrm{e} 016 \mathrm{~s}^{2}-1.972 \mathrm{e} 018 \mathrm{~s}+1.836 \mathrm{e} 009}{\mathrm{~s}^{5}+1.326 \mathrm{e} 005 \mathrm{~s}^{4}+3.43 \mathrm{e} 009 \mathrm{~s}^{3}+3.955 \mathrm{e} 013 \mathrm{~s}^{2}+8.937 \mathrm{e} 015 \mathrm{~s}+1.661 \mathrm{e} 014} \\
& \mathrm{C} 2=\frac{-3.018 \mathrm{e} 009 \mathrm{~s}^{4}-3.122 \mathrm{e} 014 \mathrm{~s}^{3}-1.271 \mathrm{e} 017 \mathrm{~s}^{2}-3.276 \mathrm{e} 018 \mathrm{~s}+4.266 \mathrm{e} 009}{\mathrm{~s}^{5}+1.442 \mathrm{e} 005 \mathrm{~s}^{4}+4.869 \mathrm{e} 009 \mathrm{~s}^{3}+6.507 \mathrm{e} 013 \mathrm{~s}^{2}+1.183 \mathrm{e} 016 \mathrm{~s}+2.196 \mathrm{e} 014} \\
& \mathrm{C} 3=\frac{-1.252 \mathrm{e} 009 \mathrm{~s}^{4}-1.294 \mathrm{e} 014 \mathrm{~s}^{3}-3.921 \mathrm{e} 016 \mathrm{~s}^{2}-9.853 \mathrm{e} 017 \mathrm{~s}-3.704 \mathrm{e} 009}{\mathrm{~s}^{5}+1.322 \mathrm{e} 005 \mathrm{~s}^{4}+3.379 \mathrm{e} 009 \mathrm{~s}^{3}+3.856 \mathrm{e} 013 \mathrm{~s}^{2}+3.776 \mathrm{e} 015 \mathrm{~s}+7.016 \mathrm{e} 013} \\
& \mathrm{C} 4=\frac{-1.002 \mathrm{e} 005 \mathrm{~s}^{4}-2.921 \mathrm{e} 007 \mathrm{~s}^{3}-1.725 \mathrm{e} 009 \mathrm{~s}^{2}-7.171 \mathrm{e} 009 \mathrm{~s}-1.307 \mathrm{e} 009}{\mathrm{~s}^{5}+685.7 \mathrm{~s}^{4}+685.7 \mathrm{~s}^{3}+6.564 \mathrm{e} 005 \mathrm{~s}^{2}+5.587 \mathrm{e} 005 \mathrm{~s}+1.933 \mathrm{e} 004}
\end{aligned}
$$

The obtained results clarify that the multiplicative reduction method yield better result which is consistent with the non reduced controller and consequently it will be used forward in this work.

\subsubsection{Robust autopilot design evaluation}

Let us consider the $6^{\text {th }}$ pitch airframe transfer function as a nominal airframe which has a moderate frequency response compared with the remainder set points.

Step response: The system step response using different design trials and the corresponding control efforts are shown in Fig. 18.

Noise Attenuation: Applying white Gaussian noise on the gyro output, the obtained control effort is shown in Fig. 19, which clarify that the robust trial-4 is less sensitive to additive noise compared to other trials.

Disturbance Rejection: Applying an impulse disturbance on the jetivator output, the obtained step response of closed loop system clarifies that the convergence using robust after applying a disturbance is the best compared to other controllers as it rejects $50 \%$ within $0.003 \mathrm{sec}$ and rejects $95 \%$ within $0.01 \mathrm{sec}$. Also, the control effort is shown in Fig. 19 which reveals that this robust controller has the lowest control effort after applying disturbance compared with PD controller obtained before.

Unmodeled Dynamics: The four designed controllers are implemented at the different trim points from which the obtained results clarify that Trial-2 is faster than others as shown in Figs. 18, 20.
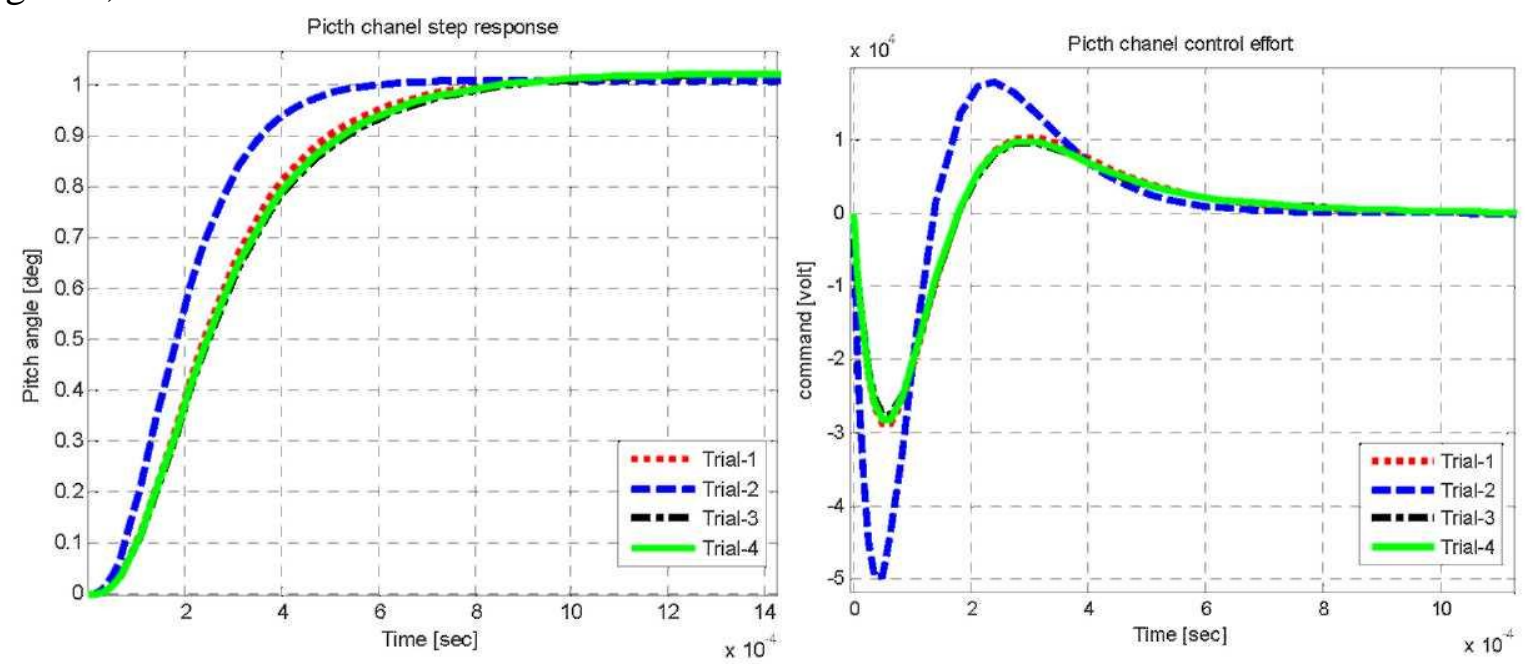

Fig. 18 (a) Step response using $\mathbf{H}_{\infty}$ (b) Control effort 

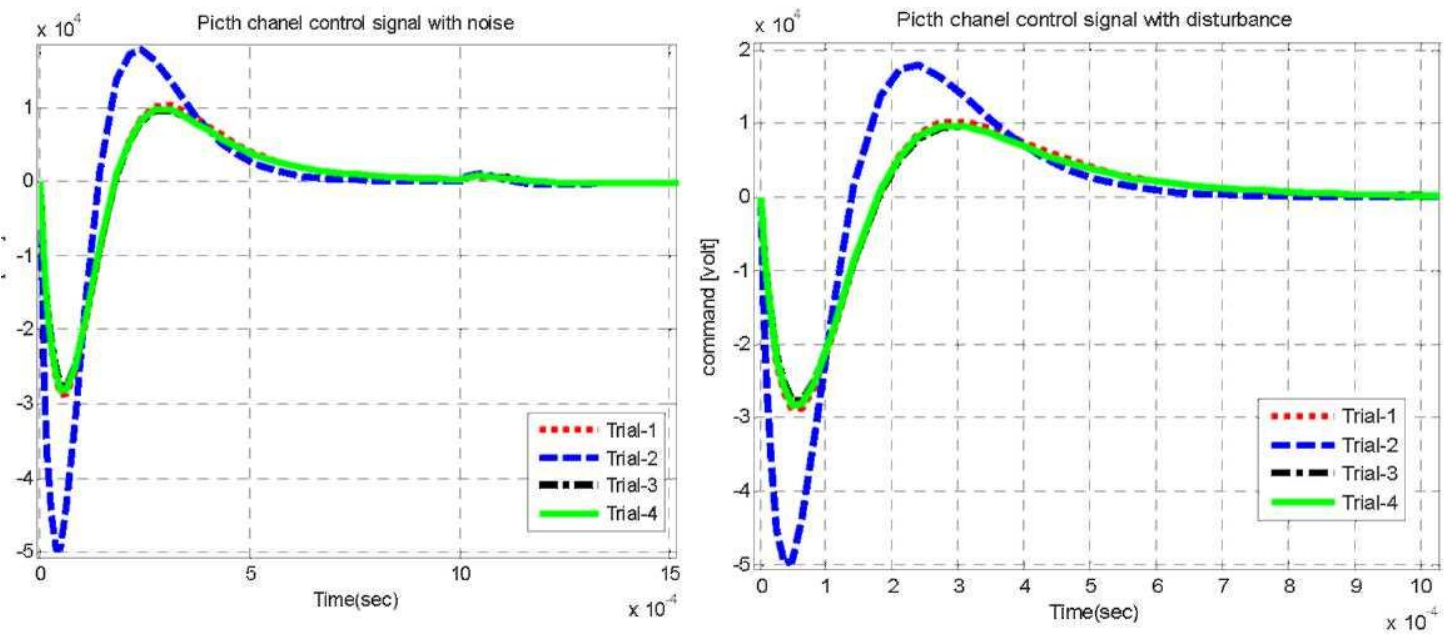

Fig. 19 Using $H_{\infty}$ : Control effort with (a) noise (b) disturbance
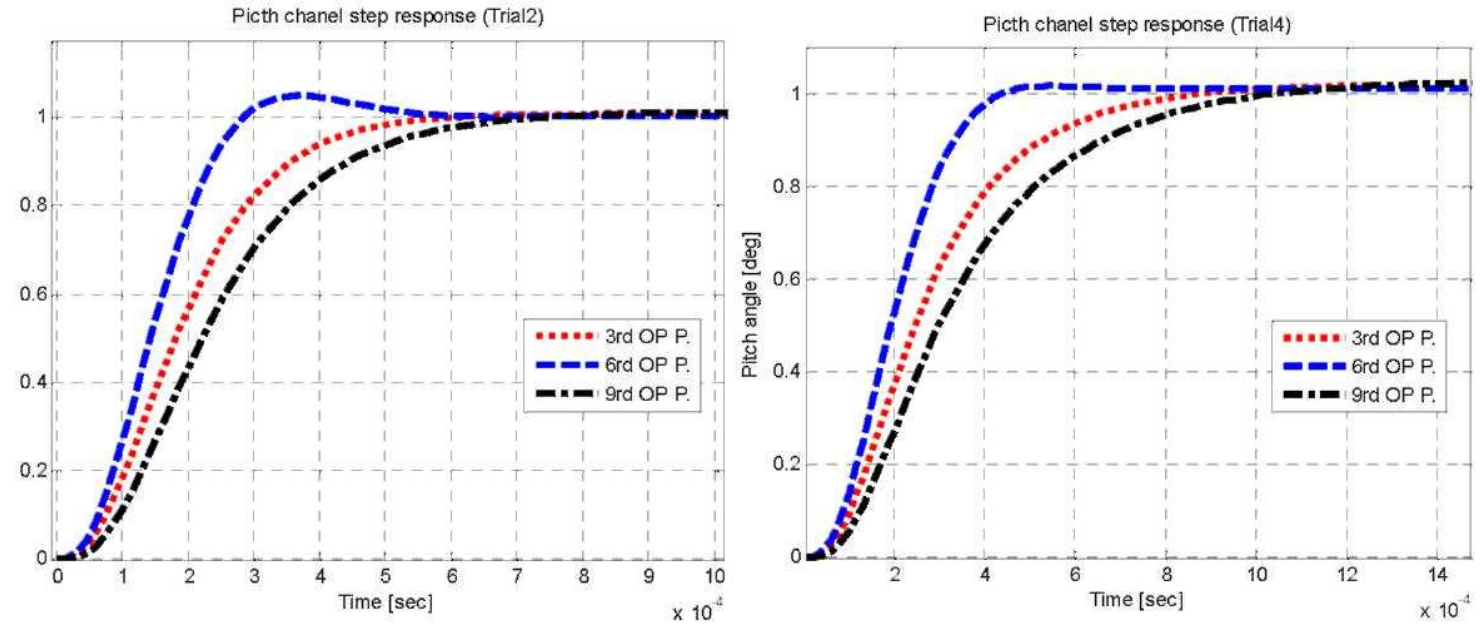

Fig. 20 Step response using design (a) Trial-2 (b) Tria-4

\section{Autopilot Designs Comparison}

\subsection{Time Responses}

The system step response using the designed autopilots (classical and $\mathrm{H}_{\infty}$ ) is shown in Fig. 21a while the corresponding control effort is shown in Fig. 21b. In addition, the system response to a step disturbance with the control effort is shown in Fig. 22.

The above results clarify that the $\mathrm{H}$ autopilot yields faster response for step input and disturbance rejection than the classical one but at the expense of larger initial control effort. However, the $\mathrm{H}_{\infty}$ control effort diminishes towards the zero faster and smoothly. 

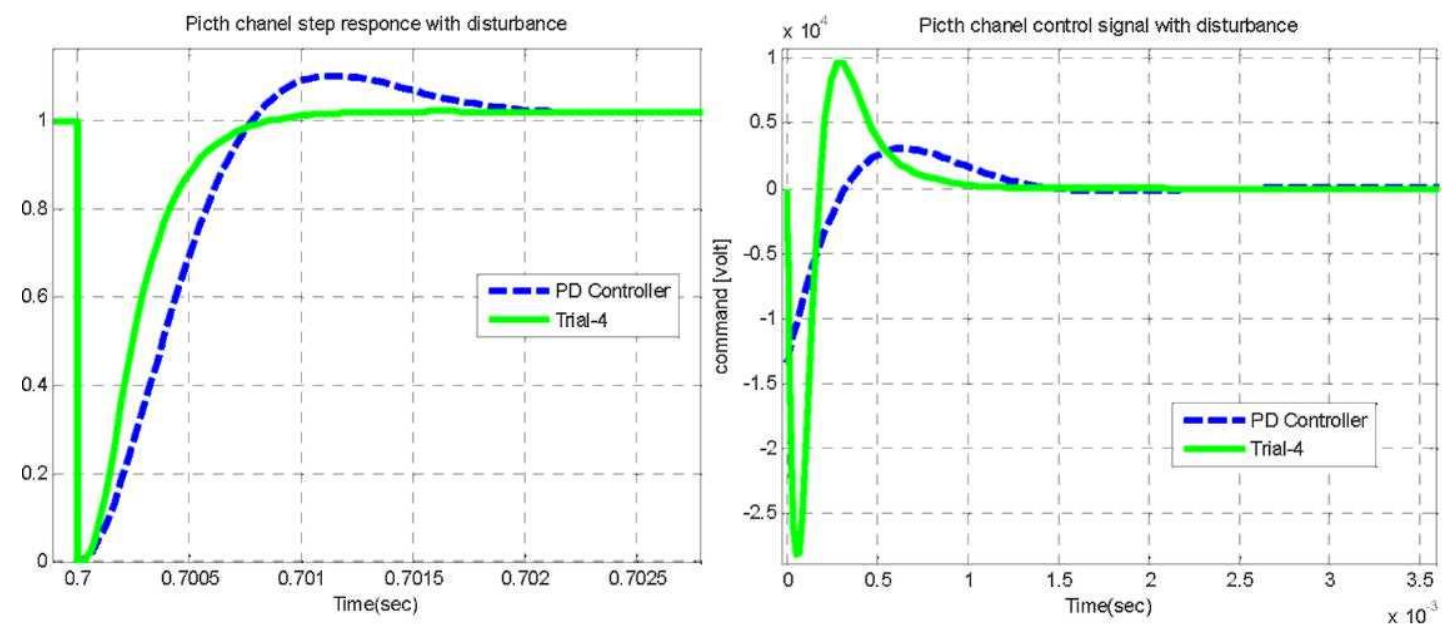

Fig. 21 Response using PD and $\mathrm{H}_{\infty}$ (a) Step (b) Control effort
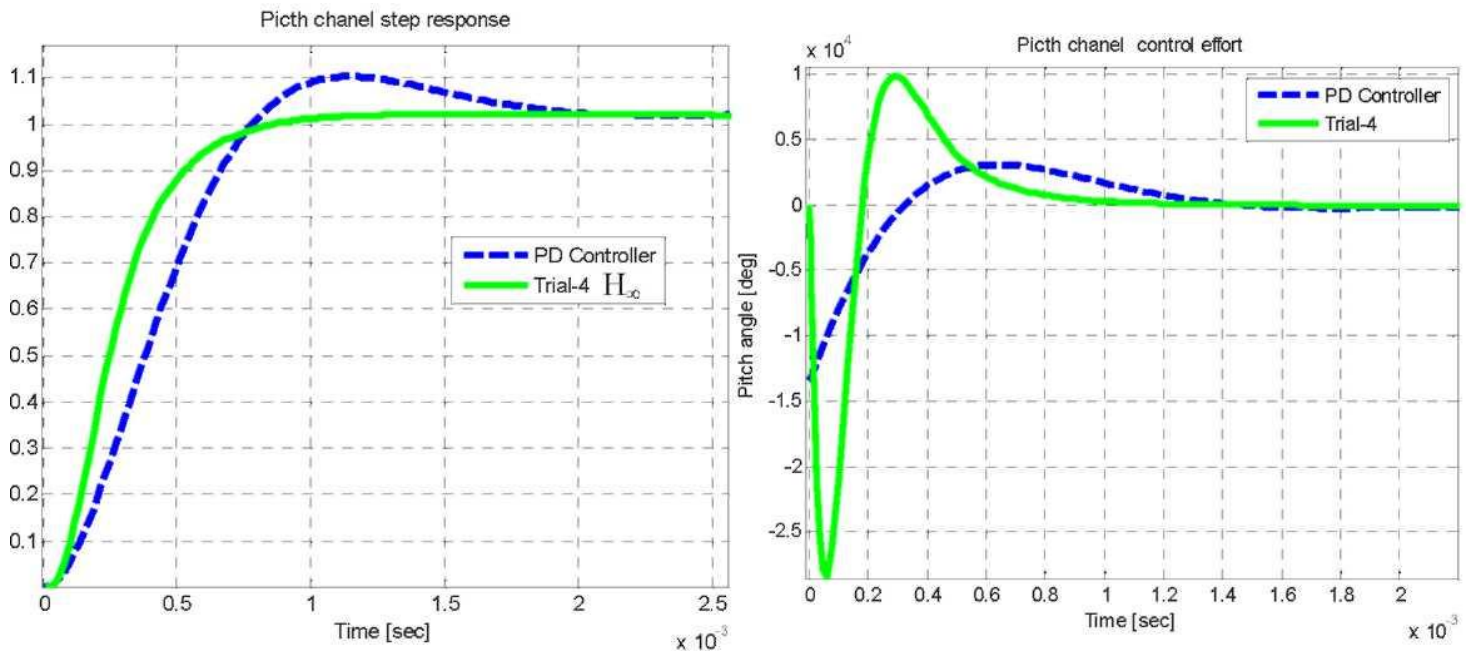

Fig. 22 Response using PD and $\mathrm{H}$ (a) Step disturbance (b) Control effort

\subsection{Flight Path Evaluation}

The designed controllers are converted into differential equations inside the 6DOF model, the simulation of which in conjunction with engagement parameters of Table (3) yield the flight path trajectories shown in Figs. 23,24.

The obtained results reveal that the designed robust trial-4 has somehow slow step response than trial-2 but it is less sensitive to the applied disturbance and noise and has a successful flight path trajectory compared to the second trial. Table (3) shows a comparison between the classical controller and the robust controllers via flight parameters. 

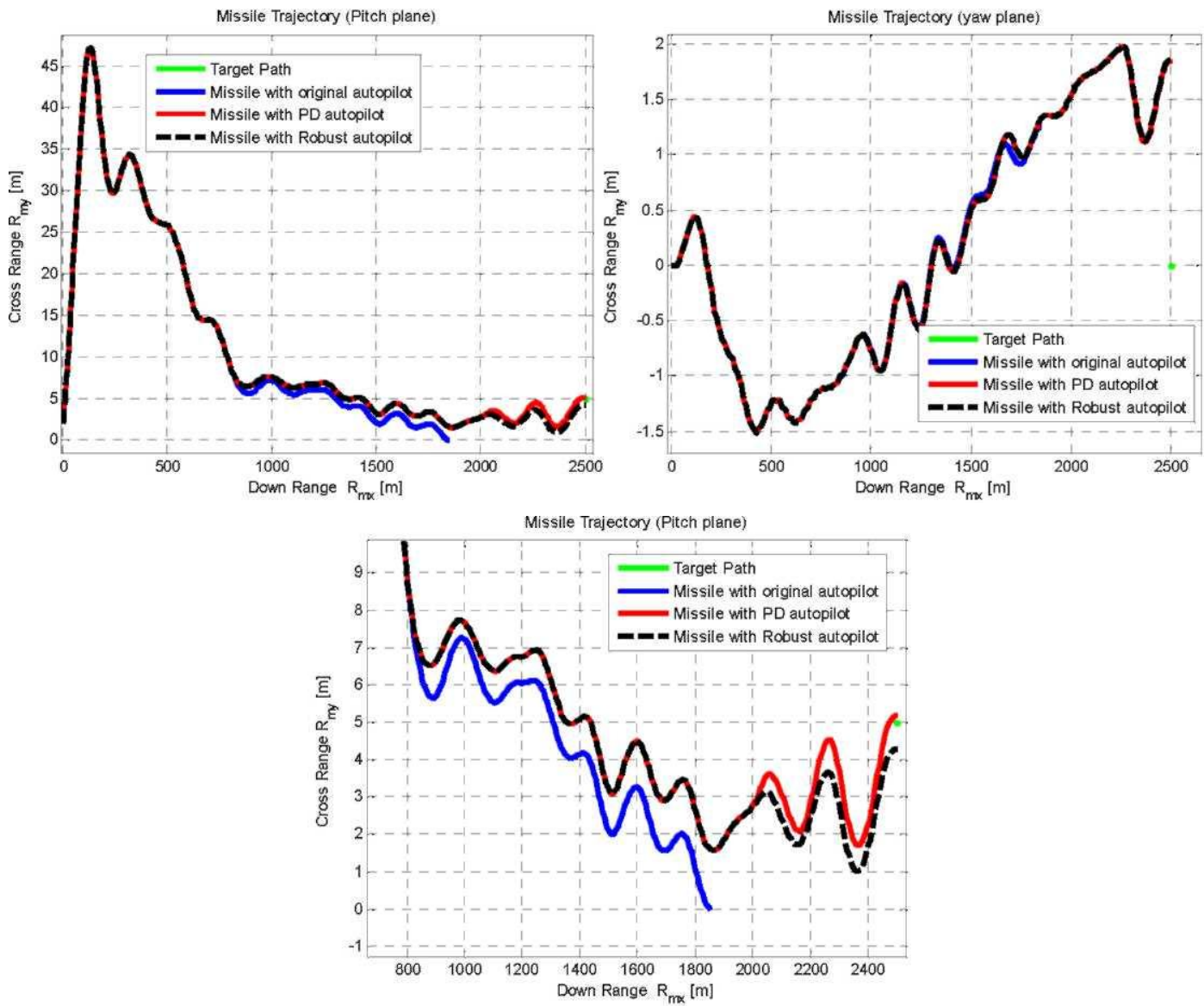

Fig. 23 Flight Path Scenario-5

Table (3) Scenarios with comparison between PD and robust autopilots

\begin{tabular}{c|c|c|c|c|c|c|c|c}
\hline \hline \multirow{2}{*}{$\begin{array}{c}\text { Engagement } \\
\text { Scenario }\end{array}$} & \multicolumn{2}{|c|}{ Target Position } & Vtz & NSR & Thrust & \multicolumn{3}{c}{ Miss-Distance } \\
\cline { 2 - 9 } & Rtk [tan] & Rtv [m] & {$[\mathrm{m} / \mathrm{sec}]$} & & {$[\mathrm{N}]$} & P & PD & Robust \\
\hline 1 & 2 & 5 & 0 & 0 & 1.06 & 1.5 & 1.33 & 1 \\
\hline$* 1$ & 2 & 10 & 8 & 0 & 1 & 1.67 & 0.95 & 0.85 \\
\hline $\mathrm{J}$ & 2.5 & 5 & 0 & 0 & 1 & 1.34 & 2 & 2 \\
\hline 4 & 3.5 & 5 & 0 & 0 & 1 & 1.22 & 2.47 & 2.85 \\
\hline 5 & 2 & 3 & 0 & 0.05 & 1 & G. Impact & 1.92 & 1.9 \\
\hline 6 & 2.5 & 5 & 8 & 0.049 & 1 & G. Impact & 2.6 & 2.4 \\
\hline 7 & 2.5 & 5 & 0 & 0.046 & 1 & G. Impact & 1.9 & 1.99 \\
\hline 8 & 3.5 & 5 & 0 & 0 & 0.95 & 2.3 & 1.1 & 0.45 \\
\hline \hline
\end{tabular}



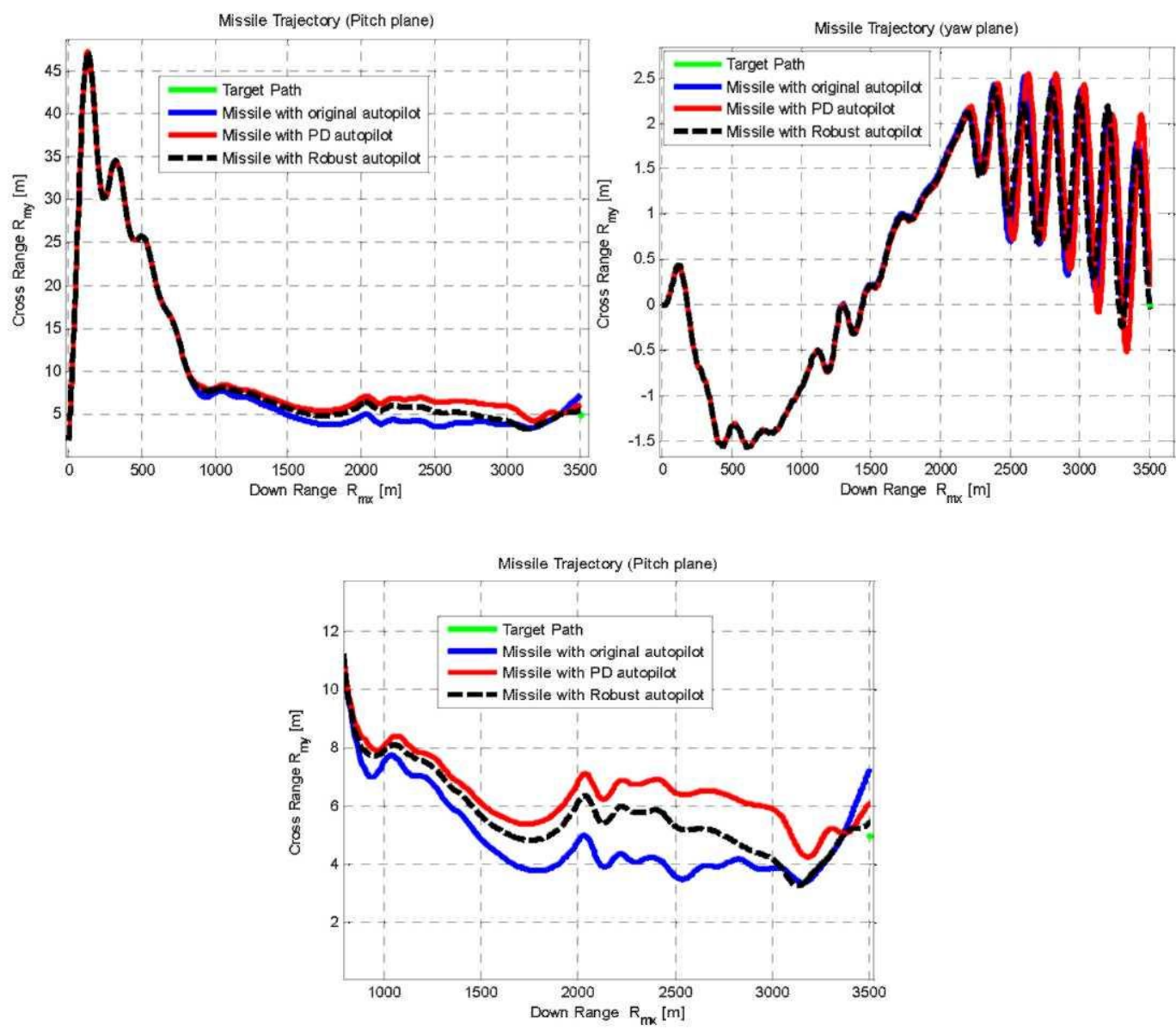

Fig. 24 Flight Path Scenario-8

\section{Conclusion}

The paper presented the modeling of the intended system concerning the reference frames, coordinates' transformations and equations of motion. This model is built in the form of modules assigned to each process within the guided missile system. Then, it is programmed within the MATLAB environments. The simulation is conducted with different engagement scenarios and different sources of uncertainties including thrust variation, errors in aerodynamic coefficients and wind velocity effects. The simulation results are validated against reference data with different levels of uncertainty which clarify appropriateness of built 6DOF model for autopilot and guidance laws design. This paper presented the derivation of linearized equations from which the different aerodynamic transfer functions are extracted and calculated at different engagement scenarios. The pitch channel controller is designed and evaluated against unmodeled dynamics, measurement noise, disturbances and flight path nonlinearzies. The obtained results clarify that the designed PD achieved less miss-distance and less control signal. Then, the paper presented the robust $H_{\infty}$ control theory with different sensitivities and norms. In addition, it presented the model reduction techniques that can be utilized for reducing the controller order and the appropriateness of multiplicative method. The autopilots designed are evaluated against unmodeled dynamics, disturbance rejection, noise attenuation and flight path. The obtained results clarify that the $H_{\infty}$ controller is more robust than the classical. 


\section{References}

[1] Abd El-Latif, M.A., Robust Guidance and Control Algorithms in Presence of Uncertainties, MSc Thesis, Guidance Department. M.T.C., Cairo, Egypt, 2006.

[2] Aly, M.S., Dynamical Analysis of Anti-Tank Missile Systems, Proceedings of the 9th int. AMME conference, 16-18 May, 2000.

[3] Aly, M.S., Linear Model Evaluation of Command Guidance Systems. Proceedings of the 8th Int. conference on aerospace science and aviation technology, pp 1001-1003, 4-6 May, 1999.

[4] Blakelock, J.B., Automatic Control of Aircraft and Missiles, Second Edition, John Wiley \& Sons 1991.

[5] El-Halwagy, Y.Z.. M.S. Aly, and M.S. Ghoniemy, Command Guidance System Simulation Airframe Analysis, Proceedings of the 7th Int. conference on aerospace science and aviation technology, 13-15 May, 1997.

[6] El-Sheikh, G.A., Guidance: Tlieon> and Systems, MTC, 2012.

[7] El-Sheikh, G.A., M.A. Abd-Altief and M.Y. Dogheish, Anti-Tank Guided Missile Performance Enhancement: Part-2: Robust Controller Design. 5th ICEENG Conference, GC-10, MTC, Cairo, Egypt, May 16-18, 2006.

[8] EL-Sheikh, G.A., M.J.Grimble, and M.A.Johanson, On the performance of $\mathrm{GH}^{\wedge}$ SelfTiming for Aero Engine Control, control-97. Warwick University, March 01-07,1997, pp 1306-1310.

[9] Gamell P. and East D. J., Guided Weapon Control Systems. 2nd edition, Pergamon press, New York, 1980.

[10] Hashad. A.I., An Enhancement System For Guidance and Control of IR Command Guided Missiles, M.Sc Thesis, Military Technical College, 1988.

[11] Hertfordshire, S., Guided Weapons, British aircraft corporation, England, May, 1975.

[12] Locke S. and East D.J.. Principles of Guided Missile Design, Van Nostraud Reinhold company Inc., 1955.

[13] Michael selig, Brian fucsz, Flight Simulation, May, 2003.

[14] Nasr Al-Hamwi, Robust Control and its Application to Antitank Guided Missile System. PhD Thesis. MTC Cairo. 2001.

[15] Puckett. A.E., and S.Ramo. Guided Missile Engineering, McGraw Hill, 1959. 